\title{
A Review of Process Systems Engineering (PSE) Tools for the Design of Ionic Liquids and Integrated Biorefineries
}

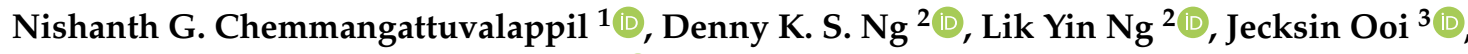 \\ Jia Wen Chong ${ }^{1}$ and Mario R. Eden ${ }^{4, *}$ \\ 1 Department of Chemical and Environmental Engineering, University of Nottingham Malaysia, \\ Jalan Broga, Semenyih 43500, Malaysia; Nishanth.C@nottingham.edu.my (N.G.C.); \\ keby5cjw@nottingham.edu.my (J.W.C.) \\ 2 School of Engineering and Physical Sciences, Heriot-Watt University Malaysia, \\ No. 1, Jalan Venna P5/2, Precinct 5, Putrajaya 62200, Malaysia; denny.ng@hw.ac.uk (D.K.S.N.); \\ l.ng@hw.ac.uk (L.Y.N.) \\ 3 Department of Chemical \& Petroleum Engineering, Faculty of Engineering, \\ Technology and Built Environment, UCSI University Kuala Lumpur, No. 1 Jalan Menara Gading, \\ UCSI Heights, Taman Connaught, Cheras 56000, Malaysia; jecksinooi@ucsiuniversity.edu.my \\ 4 Department of Chemical Engineering, Auburn University, Auburn, AL 36849, USA \\ * Correspondence: edenmar@auburn.edu; Tel.: +1-334-844-2064
}

Received: 20 November 2020; Accepted: 16 December 2020; Published: 18 December 2020

\begin{abstract}
In this review paper, a brief overview of the increasing applicability of Process Systems Engineering (PSE) tools in two research areas, which are the design of ionic liquids and the design of integrated biorefineries, is presented. The development and advances of novel computational tools and optimization approaches in recent years have enabled these applications with practical results. A general introduction to ionic liquids and their various applications is presented followed by the major challenges in the design of optimal ionic liquids. Significant improvements in computational efficiency have made it possible to provide more reliable data for optimal system design, minimize the production cost of ionic liquids, and reduce the environmental impact caused by such solvents. Hence, the development of novel computational tools and optimization tools that contribute to the design of ionic liquids have been reviewed in detail. A detailed review of the recent developments in PSE applications in the field of integrated biorefineries is then presented. Various value-added products could be processed by the integrated biorefinery aided with applications of PSE tools with the aim of enhancing the sustainability performance in terms of economic, environmental, and social impacts. The application of molecular design tools in the design of integrated biorefineries is also highlighted. Major developments in the application of ionic liquids in integrated biorefineries have been emphasized. This paper is concluded by highlighting the major opportunities for further research in these two research areas and the areas for possible integration of these research fields.
\end{abstract}

Keywords: ionic liquids; integrated biorefineries; process systems engineering; process optimization; molecular design

\section{Introduction}

The competitive nature of the current chemical industry constantly demands improvements in process and product quality and efficiency. To maximize profitability and to succeed in the global competition, the chemical processes need to be operated optimally and also need to look for better products and ways to produce them. Process Systems Engineering (PSE) tools have been instrumental in developing optimal processes and identifying better products. PSE is defined by Grossmann and 
Westerberg [1] as "the field that is concerned with the improvement of decision-making processes for the creation and operation of the chemical supply chain. It deals with the discovery, design, manufacture, and distribution of chemical products in the context of many conflicting goals." The developed approaches towards chemical process design is a major shift from the conventional focus where the emphasis was to develop tools and procedures for the process design, control, and operation. In recent decades, the focus of research in PSE fields has shifted to the areas of development of new products, process networks and enterprise, supply chain optimization, and global life cycle assessment (LCA) [2].

The development of PSE tools and methodologies has enabled the applications of these tools in various research fields. While the focus of PSE tools was more process-oriented and towards specific industrial problems in the twentieth century, the effect of globalization has prompted researchers to extend the PSE tools into new areas, e.g., development of new products, process intensification, and to address sustainability challenges. Significant improvements in computational efficiency have contributed to the application of PSE tools in several areas where historically, size-related problems had made the solutions impractical. In this paper, the application of novel PSE approaches in the design of ionic liquids and the synthesis of integrated biorefineries are highlighted. Since these are relatively recent concepts, specific PSE tools had to be developed to address the specific/novel challenges raised by these problems.

It has been recognized in recent years that ionic liquids may be a suitable replacement for several traditional solvents that pose environmental risks. The major potential areas for their application as a solvent include carbon capture, extraction, as an entrainer in extractive distillation, and also in various chemical, biochemical, electrochemical, and pharmaceutical industries [3]. Ionic liquids have unique properties that make them suitable for these industrial applications. In addition, it is possible to alter the functional groups to meet the desired attributes for various applications. The two major challenges for the design of suitable ionic liquids and the application in industries are the unavailability of reliable data and the high production cost of ionic liquids. Because of that, the ionic liquids used for various applications and the conditions at which the systems are operated may not be optimal. In order to make an optimal selection of ionic liquids, various PSE approaches (both insight-based and mathematical optimization approaches) have been developed in the past decades. The development of novel group contribution (GC) models [3], computer-aided molecular design (CAMD) tools [4], and the development of quantum mechanical (QM) tools that can be integrated with CAMD approaches [5] had been the significant breakthroughs that allow the application of PSE tools in the ionic liquid design and selection.

In addition to the design and selection of ionic liquids, the development and application of PSE tools in the field of integrated biorefineries have been immense. In recent years, biomass utilization has shown promising results in addressing society's dependence on non-renewable energy resources and climate change caused by fossil fuel exploitation. Other than being utilized for heat generation through direct combustion, the nature of biomass enables it to be converted into other value-added products ranging from biomaterials, biofuel, bio-chemicals, biopharmaceuticals, etc. Through different biomass conversion technologies (physical, mechanical, chemical, and biological), biomass can be converted into other forms of energy products such as transportation fuels, or value-added products like commodities and specialty chemicals. In the past decades, the development of single biomass conversation systems such as gasification, fermentation, digestion, etc., has been established. However, due to the complexity and diversity of biomass in nature, a single biomass conversion system is typically not able to fully recover the potential of the biomass. In view of this, integrated biorefineries is a fast-developing research area that integrates a variety of technologies to convert biomass into the abovementioned value-added products [6]. As integrated biorefinery is able to integrate multiple technologies as a single integrated system, such a system provides more flexibility in product generation and generates sufficient energy to support the entire operation and reduce the overall energy consumption compared to the processes that operate independently. In addition, with the integration of multiple technologies, the waste/by-products can be used as feedstock for another process, therefore, the material recovery can 
be maximized as shown in Figure 1. Various research works [6-10] have been presented to optimize the synthesis and design of integrated biorefineries, ranging from insight-based approaches to complex mathematical optimization models, which is discussed in Section 3.

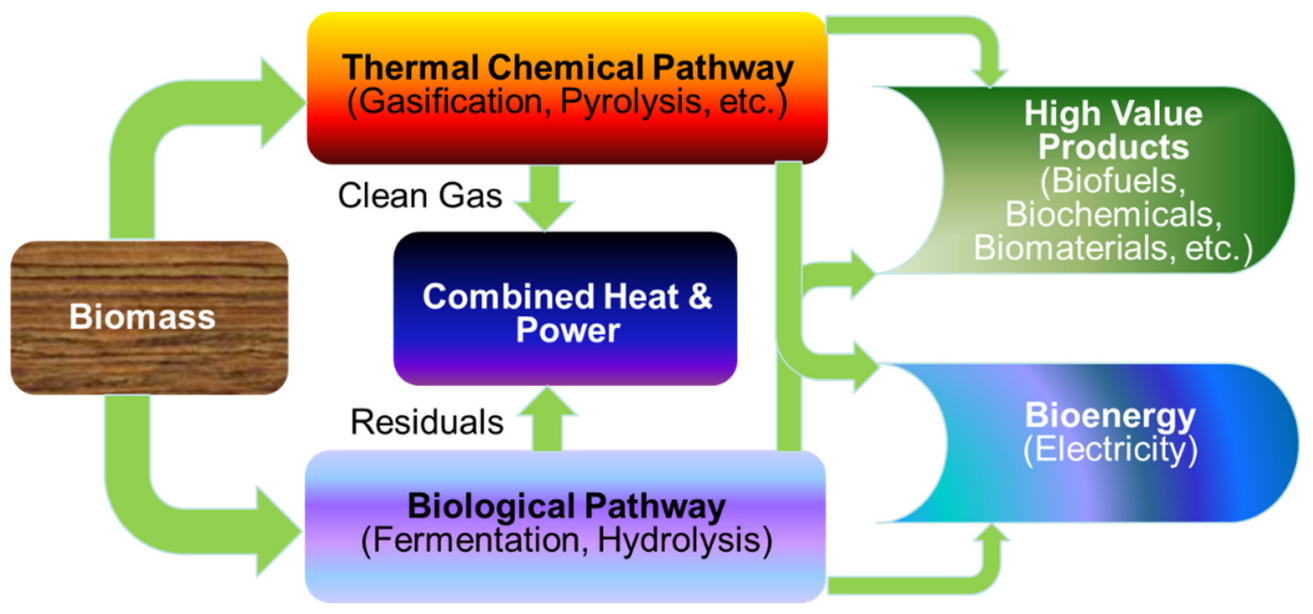

Figure 1. The integrated biorefinery concept.

In summary, advances in computing, data science, and optimization have allowed researchers to extend the application of PSE tools in several novel areas. In this paper, the application of PSE tools in the synthesis and design of ionic liquids, as well as integrated biorefineries, are to be reviewed. A general overview of these two research areas is provided followed by a detailed review of the recent development and application of PSE tools in the area. The major research challenges and the approaches used by the PSE community in addressing the identified challenges are highlighted in this paper. This review also focuses on the integration of these research fields where the role of ionic liquids as solvents in integrated biorefineries has been analyzed. Finally, the paper identifies some of the research scopes for further research and the way forward.

\section{Applications of PSE in the Development of New and Green Chemicals}

In this section, an introduction to ionic liquids and their potential applications is presented. A comprehensive review of the applications of ionic liquids in various industries is also provided. Furthermore, the latest developments and contributions in the field of ionic liquid design are reviewed. In addition, the challenges and limitations encountered in the design of optimal ionic liquids are discussed. Lastly, the recent applications of CAMD in the ionic liquid design are reviewed in detail.

\subsection{Ionic Liquids}

Ionic liquids are organic salts that comprise organic cations with inorganic or organic anions and melt at temperatures below $100{ }^{\circ} \mathrm{C}$. They were first introduced by Paul Walden in 1914 when he successfully synthesized ethyl ammonium nitrate which melts at room temperature [11]. The introduction of ionic liquids has attracted considerable attention from researchers, especially in replacing traditional solvents with ionic liquids due to their extraordinary characteristics. For example, ionic liquids are known to exhibit non-flammability, as well as high thermal and chemical stabilities owing to the strong ionic bonds [12]. Besides, ionic liquids also possess the attributes of "green" solvents since their vapor pressure is significantly lower than the conventional solvents. The high volatility of conventional organic solvents can cause air pollution and human health problems if they leak from process equipment.

Ionic liquids are widely recognized as "designer" solvents because of the flexibility in turning their properties by altering the cations. For instance, their melting point can be reduced by having large asymmetric organic cations [13]. By selecting various combinations of anions and cations, 
ionic liquids with an attractive set of physicochemical properties can be synthesized. In addition, ionic liquids' capabilities, which include a wide range of intermolecular interactions such as hydrogen bonding, ionic and covalent interactions as well as $\pi$-stacking, have also contributed to their tunable properties [14]. For these reasons, they have huge potential to reduce the environmental impact caused by organic solvents. Nonetheless, the major drawback of applying ionic liquids in various chemical processes is their high purification cost. As ionic liquids consist of highly charged ions, the ionic liquid recovery and purification process becomes difficult and cost-intensive [15]. In spite of the high recovery and purification cost, the unique properties of ionic liquids are still important and attractive from an industrial point of view. This can, at least in part, be seen by an increasing number of patent filings, especially related to the applications of ionic liquids [16]. Moreover, there is also an exponential increase in Science Citation Index (SCI) papers published on ionic liquids in the last few decades [17]. For these reasons, it is feasible that ionic liquids can become viable options for various applications and industrial processes.

\subsection{Potential Applications of Ionic Liquids}

In recent years, there is a surge in the applications of ionic liquids in various industries. Table 1 shows some potential applications of ionic liquids that will be discussed in detail in this section.

Table 1. Summary of potential applications of ionic liquids discussed in this review.

\begin{tabular}{ll}
\hline \multicolumn{1}{c}{ Types of Ionic Liquids } & \multicolumn{1}{c}{ Applications } \\
\hline 1-methylimidazolium chloride & Biphasic acid scavenging [18] \\
\hline 1-butylpyridinium tetrafluoroborate & Geothermal fluid in organic Rankine cycle [19] \\
\hline 1-ethyl-3-methylimidazolium bis(trifluoromethylsulfonyl)imide & Hydrogen compressor [20] \\
\hline 1-Ethyl-3-methylimidazolium acetate & Sugarcane bagasse pre-treatment [21] \\
\hline $\begin{array}{l}\text { 1-butyl-3-methylimidazolium chloride and } \\
\text { 1-butyl-3-methylimidazolium acetate }\end{array}$ & Rubber woods pre-treatment [22] \\
\hline 1-butylimidazolium hydrogen sulfate (VI) & Kraft lignin activator [23] \\
\hline 1,3-dibutyl-2-methylimidazoliumbromide & Flavonoids extraction [24] \\
\hline $\begin{array}{l}\text { 1-hydroxyethyl-3-methylimidazoliumbis } \\
\text { trifluoromethanesulfonyl)amide }\end{array}$ & Keratin extraction [25] \\
\hline 1-Ethyl-3-methylimidazolium methylsulfate & Ethyl acetate and ethanol azeotropic distillation [26] \\
\hline 1-butyl-4-methylpyridinium tricyanomethanide & Cyclohexane and benzene azeotropic distillation [27] \\
\hline 1-ethyl-3-methylimmidazolium-ethylsulphate & Carbon dioxide and hydrogen sulfide separation [28] \\
\hline 1-butyl-3-propylamineimidazolium tetrafluoroborate & Carbon dioxide capture [29] \\
\hline 1-butyl-3-methylimidazolium hexafluorophosphate & Carbon dioxide capture [30] \\
\hline Tetraglyme-sodium salt ionic liquids & Sulfur dioxide separation [31] \\
\hline 1-butyl imidazolium bis(trifluoromethylsulfonyl)imide & Ammonia separation [32] \\
\hline $\begin{array}{l}\text { Bis(1-butyl-3-methyl imidazolium) copper tetrachloride salt and } \\
\text { bis(1-butyl-3-methyl imidazolium) stannum tetrachloride salt }\end{array}$ & Ammonia separation [33] \\
\hline
\end{tabular}

The first industrial application of ionic liquids, called the BASIL process, was developed by BASF [18]. This process is mainly used for producing generic photo initiator precursor alkoxy phenyl phosphines. It is the first commercial publicly announced process that uses an ionic liquid (named 1-methylimidazolium chloride) to scavenge acid from reaction mixtures. The extraordinary properties of ionic liquids are also advantageous for several reactions such as bio-catalyzed reaction, dimerization, isomerization, hydrogenation, hydroformylations, and alkylation [34]. Higher reaction rates and selectivity can be achieved when organic solvents are replaced with ionic liquid solvents. For instance, the hydrolysis rate of casein by lumbrokinase is enhanced when ionic liquids are added to the reaction [35]. The existence of ionic liquids at low concentrations improves the hydrophilicity of casein by forming an ionic liquid-casein complex. 
Ionic liquids have also been reported as excellent candidates for heat transfer fluids owing to their low flammability, high heat stability, and low volatility characteristics. When ionic liquids were used as heat transfer fluids in shell and tube heat exchangers, a comparable or larger heat transfer area can be achieved compared to other heat transfer fluids [36]. The ionic liquid, 1-butyl pyridinium tetrafluoroborate $\left(\mathrm{C}_{9} \mathrm{H}_{14} \mathrm{NBF}_{4}\right)$ was used as a geothermal fluid in an organic Rankine cycle was explored by Kazemi et al. [19]. Optimization and simulation work was carried out for a basic organic Rankine cycle using $\mathrm{C}_{9} \mathrm{H}_{14} \mathrm{NBF}_{4}$ and water as the geothermal fluids, respectively. In their study, economic, thermodynamic, and thermo-economic evaluations were chosen as objective functions for minimizing specific investment costs and maximizing exergy efficiency. The results indicated that the basic organic Rankine cycle performance was improved thermodynamically and economically when $\mathrm{C}_{9} \mathrm{H}_{14} \mathrm{NBF}_{4}$ was used as a geothermal fluid.

Moreover, ionic liquids have a high tendency to wet inorganic, metal, and polymeric surfaces [34]. With their wide liquidus range and high thermal stability, ionic liquids are ideal candidates to be used as lubricants in low pressure and/or high-temperature applications. Other than the aforementioned properties, ionic liquids are also applied as lubricating media in oxygen compressors due to their good lubricity and high chemical inertness [37]. Based on the long-term test conducted with pure oxygen, the result is both impressive and promising as the hydrocarbon concentrations in all tests were below 10 ppmv methane equivalents, which is beyond the threshold value of $1000 \mathrm{ppmv}$. In another recent study, it was proposed that the solid piston in reciprocating hydrogen compressors may be replaced by ionic liquids [20]. By replacing the solid piston in reciprocating compressors with a suitable liquid, efficiency can be improved along with significant cost reduction.

Apart from being suitable candidates for lubricants and thermal transfer fluids, ionic liquids have also been introduced in biomass conversion applications, such as lignocellulose pretreatment and fractionation. Most existing molecular solvents are not able to dissolve and hydrolyze cellulose into fermentable sugars as the cellulose chains are interconnected by strong hydrogen bonding in flat sheets [38]. Nonetheless, various ionic liquids have demonstrated their capabilities in dissolving and fractionating lignocellulose into its main constituent compounds. For example, cellulose isolated from sugarcane bagasse was pretreated with an ionic liquid called 1-Ethyl-3-methylimidazolium acetate ([Emim]Ac) at $90^{\circ} \mathrm{C}$ prior to hydrolysis by cellulase [21]. After the pretreatment process, the glucose content is increased whereas the crystallinity index and degree of polymerization are reduced. The cellulose crystal structure has also transformed from cellulose I to cellulose II. These changes have enhanced enzymatic hydrolysis rate and glucose production yield. Furthermore, the effect of pretreating rubber woods with ionic liquids on thermodynamic properties and pyrolysis kinetics was explored by Khan et al. [22]. The pretreatment of rubber woods with both ionic liquids, 1-butyl-3-methylimidazolium chloride ([BMim] $[\mathrm{Cl}])$ and 1-butyl-3-methylimidazolium acetate ([BMIM][OAc]) successfully reduced the activation energy required for the pyrolysis reaction. Moreover, ionic liquids have also shown their potential in kraft lignin activation processes. After activating kraft lignin with ionic liquids, a better electrochemical performance was observed due to an increase in carbonyl groups, which are responsible for transporting protons and electrons in electrochemical applications [23].

Considering stringent environmental regulations as well as increased emphasis on green and clean manufacturing practices, ionic liquids have gained popularity in extraction processes. This is because most of the common organic solvents used in extraction processes are toxic and flammable, which leads to detrimental environmental issues when released into the atmosphere. The use of ionic liquids in extraction processes typically leads to shorter processing time and most importantly, the process can often be carried out at ambient temperature [39]. For this reason, the application of ionic liquid is widely found in the extraction and purification of bioactive compounds such as proteins, lipids, amino acids, and pharmaceuticals. Novel dual-chain ionic liquids were synthesized and applied to recover flavonoids from Pinus massoniana Lamb [24]. The results showed that ionic liquids are more efficient in extracting flavonoids than water and ethanol. In another study, a hydrophobic ionic liquid was shown to be capable of extracting keratin from chicken feathers [25]. The water extraction method 
can be used to isolate keratin from the ionic liquid as hydrophobic ionic liquid is insoluble in water while keratin is soluble in water.

A classic challenge in the process has been to choose a suitable entrainer in separating azeotropic mixtures. Ionic liquids have been suggested as potential entrainers in an azeotropic system since their selectivity, capacity and thermal stability can be easily altered [40]. For example, Zhu et al. [26] performed a process simulation study of ionic liquids applied in an extractive distillation process to separate an ethyl acetate and ethanol mixture, which have close boiling points. The results showed that 1-Ethyl-3-methylimidazolium methyl sulfate was the best solvent for this separation. In another contribution, 1-butyl-4-methyl pyridinium tricyanomethanide ([4bmpy][TCM]) has been proposed as an entrainer in the extractive distillation process to separate cyclohexane and benzene [27] as overall solvent consumption can be reduced. Another contribution evaluated the capability of protic ionic liquids as an entrainer to separate ethanol-water azeotropic mixtures [41]. In this process, the relative volatility between ethanol and water is increased and the complete azeotrope elimination was achieved. Conductor-like screening model for real solvents (COSMO-RS) was used to study the intermolecular interactions between the binary ethanol-water and the ternary ethanol-water-protic ionic liquids mixtures. The results were in agreement with the experimental values.

The possibility of using ionic liquids to separate liquids was explored by Fadeev and Meagher [42], where an ionic liquid was used to recover butyl alcohol from a fermentation broth. Ionic liquids are also reported to be efficient in gas separation. Due to their hygroscopic nature, ionic liquids can remove water vapor efficiently from gas mixtures [43]. Likewise, the solubility of gas can be altered by the proper selection of cation, anion, and substituents. For example, when certain anions are used and the alkyl chain is shortened, the Henry's Law constant of carbon dioxide is reduced to half [34]. Based on the experiments performed by Anthony et al. [44], gases were found to have different solubilities in ionic liquids, suggesting that there is a great potential for designing ionic liquids to be used in specific gas separations.

Carbon dioxide $\left(\mathrm{CO}_{2}\right)$ was first reported to be highly soluble in imidazolium-based ionic liquids like 1-butyl-3-methylimidazolium hexafluorophosphate by Blanchard et al. [30]. The finding reported that the dissolution of $\mathrm{CO}_{2}$ in imidazolium-based ionic liquids is totally reversible meaning that pure ionic liquids can be easily recovered after the desorption process. Since then, there has been an increasing number of scientific studies investigating the capability of ionic liquid compounds in capturing $\mathrm{CO}_{2}$. The efficiency of a new task-specific ionic liquid, which is an amino-functionalized ionic liquid named 1-butyl-3-propylamineimidazolium tetrafluoroborate ([ $\mathrm{NH}_{2} \mathrm{p}$-bim] $\left.\left[\mathrm{BF}_{4}\right]\right)$, was comparable to conventional solvents in $\mathrm{CO}_{2}$ absorption processes [12]. To maximize the interaction sites for $\mathrm{CO}_{2}$ capture, a dual amino ionic liquid that contains a taurine anion and amino-functionalized imidazolium cation has been synthesized [45]. The result reported that 1 mole of the ionic liquid can absorb 0.9 mol of $\mathrm{CO}_{2}$ at atmospheric pressure. Besides, the application of both an ionic liquid and a zeolitic imidazolate framework (ZIF) as a separating agent in adsorptive absorption has demonstrated its capability in capturing $\mathrm{CO}_{2}$ [29]. The experimental and modeling results showed that $\mathrm{CO}_{2}$ is more soluble in the ionic liquid and ZIF mixture compared to that of pure ionic liquid.

Ionic liquids have also been introduced for absorbing other environmentally polluting gases such as hydrogen sulfide, ammonia, and sulfur dioxide. A mixed matrix membrane with imidazolium-based ionic liquids blended with poly ether-block-amide elastomer was synthesized for $\mathrm{CO}_{2}$ and $\mathrm{H}_{2} \mathrm{~S}$ separation [28]. This study showed that the chosen ionic liquid has higher $\mathrm{H}_{2} \mathrm{~S}$ selectivity than $\mathrm{CO}_{2}$. In another contribution, tetraglyme-sodium salt ionic liquids which possess high thermal stability appeared to be potential candidates for $\mathrm{SO}_{2}$ absorption [31]. The experimental results showed that $\mathrm{SO}_{2}$ absorption capacity improved by $30 \%$ when tetraglyme-sodium salt ionic liquids were used instead of tetraglyme. Three different types of ionic liquid including traditional ionic liquids, protic ionic liquids, and Brønsted acidic ionic liquids were synthesized and investigated for $\mathrm{NH}_{3}$ absorption [32]. Among the investigated ionic liquids, the protic ionic liquid (1-butyl imidazolium bis(trifluoromethylsulfonyl)imide ([Bim][ $\left.\left.\mathrm{NTf}_{2}\right]\right)$ ) achieved the highest $\mathrm{NH}_{3}$ absorption capacity. 1 mole 
of [Bim][ $\mathrm{NTf}_{2}$ ] was able to absorb 2.69 moles of $\mathrm{NH}_{3}$ at ambient pressure. Another study synthesized a series of metal ionic liquids and explored their potential for $\mathrm{NH}_{3}$ separation [33]. Bis(1-butyl-3-methyl imidazolium) copper tetrachloride salt ([Bmim $\left.]_{2}\left[\mathrm{CuCl}_{4}\right]\right)$ and bis(1-butyl-3-methyl imidazolium) stannum tetrachloride salt $\left([\mathrm{Bmim}]_{2}\left[\mathrm{SnCl}_{4}\right]\right)$ showed great potential for $\mathrm{NH}_{3}$ separation due to their high selectivity and absorption capacities.

The abovementioned works illustrate that ionic liquids have been extensively explored for various applications. Nonetheless, considering that an enormous number of ionic liquids can be synthesized by combining various organic cations and anions, it is difficult to select the optimum candidate(s) from this huge search space. Experimentally testing random ionic liquid combinations is both time consuming and costly. Thus, in order to minimize the time and expense required in performing experiments, various theoretical/computational methods have been proposed to guide the ionic liquids screening process preceding an experimental campaign. The following section presents the latest developments and challenges in the design of optimal ionic liquids.

\subsection{Challenges in the Design of Optimal Ionic Liquids}

In order to design ionic liquids that suit a certain industrial application, it is first important to know how the anion, cation, and side chains on the cation affect physicochemical properties. This can be done through two pathways, either via experimental work or simulation approaches. Considering a very huge number of possible ionic liquids, it would be a very tedious task to select an optimum candidate through experimentation. Because of this, researchers have been working on developing systematic computer simulation methods including CAMD and/or process design simulations to design optimal ionic liquids. Computer-aided methods provide alternative routes in determining potential ionic liquids as they can explore a larger number of options in a shorter time frame. However, it does not mean that computer-aided methods can replace experiments entirely as identified candidates should be further tested via experiments to verify their performance.

CAMD techniques are shown to be effective in designing various types of chemical, biochemical, and material products. It is able to design molecular structures that meet a predefined property target. The success of employing the CAMD technique to design ionic liquids depends greatly on the availability and reliability of the associated/underlying predictive models. Only when thermophysical properties such as density and viscosity (which influence mass transfer rates) are satisfactorily characterized, can optimal ionic liquids and/or the process in which they are used be designed [46]. Despite the availability of significant thermophysical property data for an extensive range of ionic liquids in the free ILThermo database [47], predictive models for most thermophysical properties with adequate accuracy are still being developed [48]. The availability of adequate predictive models is important in the design/development of new processes, improvement of operating conditions in a process, and reduction of energy consumption [48]. Various approaches have been proposed to develop property prediction models for thermophysical and transport properties of ionic liquids. These approaches can be categorized into two main classes which include both theoretical and empirical methods [49]. The property prediction models classified under theoretical approaches include molecular dynamics (MD) simulations, equations of state (EOS), Monte Carlo (MC) simulations as well as rough hard-sphere theory (RHST). On the other hand, machine learning (ML) tools, GC methods, and quantitative structure-property relationships (QSPR) are considered empirical approaches. These prediction models are all widely applied in predicting physicochemical properties of ionic liquids, which include density, viscosity, thermal conductivity, surface tension, heat capacity, etc. A comprehensive review of the current developments in prediction models for pure ionic liquids was presented by Hosseini et al. [48]. Moreover, Hosseini et al. [48] also reviewed the most extensively applied semi-classical EOSs in estimating thermodynamic and physical properties of pure ionic liquids. EOSs are typically developed from empirical, theoretical, and semi-theoretical approaches. Semi-classical EOSs are developed from a combination of molecular thermodynamic theories of fluid (theoretical EOSs) and classical thermodynamic approaches (empirical EOSs). Nonetheless, most of 
these existing prediction models for thermodynamic properties are limited to only a relatively small number of common families of ionic liquids.

To alleviate the limitations mentioned above, Chen et al. [3] presented newly developed GC models that are capable of estimating thermodynamic and physical properties for additional families of ionic liquids. The thermophysical properties include heat capacity, viscosity, surface tension, density as well as the melting point of the ionic liquids. New correlation equations with higher prediction accuracy that are easier have been proposed for the prediction of the aforementioned properties. The GC parameters were developed based on more than 13,300 experimental data points, including approximately 200 ionic liquids derived from 19 anions, 6 cations, and 4 substituents covering a large range of pressure and temperature conditions. These newly developed GC models offer the opportunity of applying them for CAMD to identify more potential ionic liquids solutions. Additionally, there is great potential for extending these methods to even more families of ionic liquids once experimental data become available.

With increasing awareness of environmental detriments, it is important to also consider environmental properties during the ionic liquid design stage. Since ionic liquids are normally highly soluble in an aqueous medium, they are readily discharged into the environment through wastewater [50]. Hence, the designed ionic liquids need to be environmentally friendly before they start accumulating in the environment. For this reason, various quantitative structure-activity response (QSAR) models were developed to assess the toxicity of ionic liquids. Recently, a comprehensive review of the expansion of QSAR models for toxicity prediction of ionic liquids was presented by Abramenko et al. [51]. The review concluded that the toxicity of ionic liquids is not solely reliant on the type of cation but increases with the length of the cation alkyl chain and the number of cation chain group branches. It was also found that the toxicity of ionic liquid is reduced with the presence of a polar side chain. Furthermore, the presence of polar side chains was found to increase the efficiency of biodegradation. However, most existing models for ionic liquid toxicity prediction only cover a small number of ionic liquids.

It is notable that pure ionic liquids may not always be the optimal candidates in satisfying the target properties, however, it is possible that ionic liquid mixtures could assist in addressing such problems. Unfortunately, property prediction models for ionic liquid mixtures are limited as this research area is still in its infancy. In a recent contribution, equations of state and artificial neural networks (ANN) were combined to predict volumetric properties of a limited number of pure and mixtures of amino acid ionic liquids [52]. Another contribution explored the behavior of some properties such as viscosity, diffusion coefficient, and electrical conductivity for binary mixtures of protic-protic ionic liquids as well as protic-aprotic ionic liquids [53]. The results presented that the electrical conductivity of ionic liquid mixtures is higher than that of the pure ionic liquids. Efforts have been devoted to developing property prediction models for ionic liquid mixtures, but the models are limited to only certain classes of ionic liquids. Future research should focus on developing reliable property prediction models for different families of ionic liquid mixtures.

\subsection{CAMD for Ionic Liquid Design}

The development of CAMD tools for the ionic liquid design has been limited due to the lack of accurate models in estimating ionic liquid properties. Most of the earlier work in the modeling of ionic liquids was based on molecular dynamics tools and quantum chemistry study. While these tools show reasonably accurate and reliable results, the computational time needed to complete the simulation of each candidate molecule is large. So, the applicability of these tools is more appropriate towards the final selection from a limited number of promising molecules. An early application of CAMD in ionic liquid design was the design of a suitable ionic liquid to be used in a refrigerant gas separation system. This work used molecular connectivity index based QSPR models to link the structure of the ionic liquids to target properties like diffusivity, Henry's law constant, and solubility [54]. A CAMD problem is formulated to determine the molecular structures is then formulated as a MILP. 
Another earlier application of CAMD tools for the design of ionic liquid was the extension of existing CAMD approaches based on GC models [4]. The original MINLP problem was decomposed into a set of sub-problems to reduce the complexity of the model. This approach solves one sub-problem each for structural constraints, physical property constraints, and mixture property constraints. Each of these sub-problems can eliminate several infeasible structures. The solutions obtained through the sub-problems are considered in a final sub-problem to solve for the optimum ionic liquid molecule based on the objective function and process models.

Figure 2 shows the general framework of ionic liquid design via CAMD. The procedure starts with an ionic liquid design problem definition where the product needs are identified. These requirements are then translated into targeted properties which will be validated using a model-based approach. Next, an extensive search of ionic liquids is conducted. The information collected from a vast number of literature sources and online databases is stored in the ionic liquid library. Various property models are also collected and stored in the property model library. In Step 4, UNIFAC and/or COSMO models are used to screen and predict ionic liquid with desirable properties. Lastly, the performance of the shortlisted ionic liquid candidates is validated either by experiments or simulations. This step is crucial to ensure that the ionic liquids identified are feasible and practical.

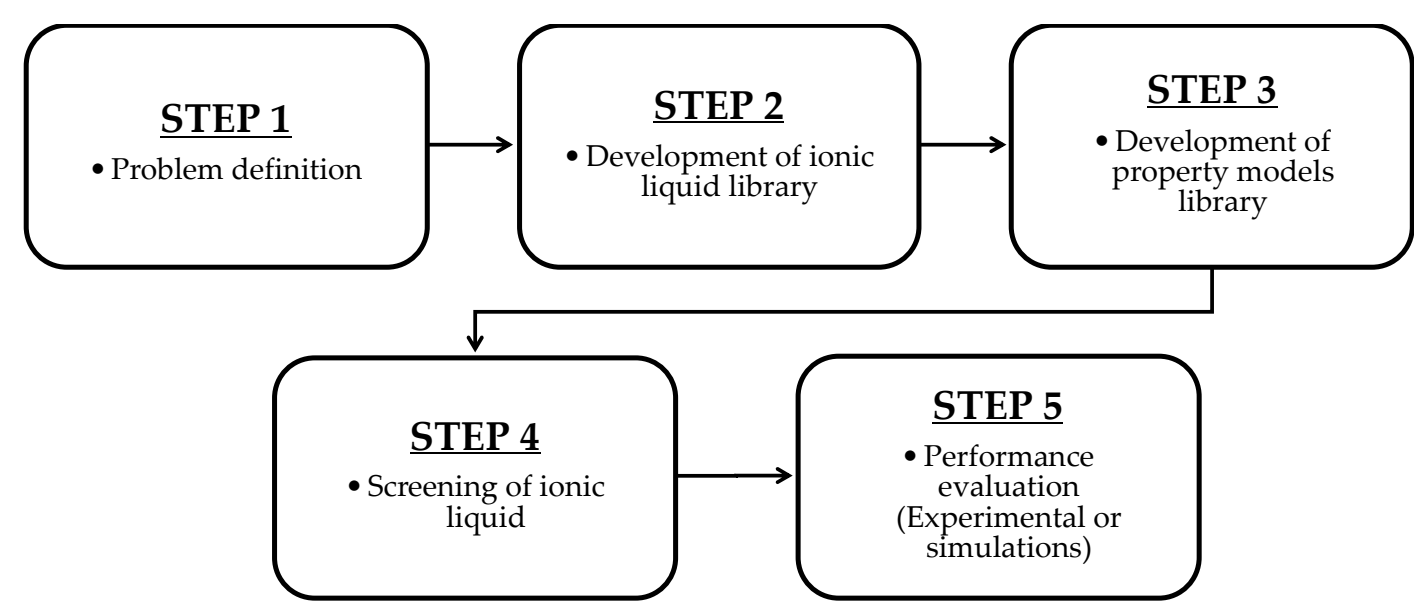

Figure 2. General framework of ionic liquid design via a computer-aided molecular design (CAMD) approach.

The application of GC-based models in CAMD has been well established and there are efficient algorithms for solving CAMD problems with different target properties. A comprehensive review of these works can be seen in the reviews of Austin et al. [55] and Chemmangattuvalappil [56]. In order to provide an accurate prediction of properties using GC models, the binary interaction parameters need to be obtained. QM calculations have been incorporated into several CAMD algorithms to address this issue in recent years [56]. One of the most popular advances in CAMD is the application of COSMO-based methods as the information of binary interaction parameters is not necessary [5]. COSMO-RS [57] and COSMO-SAC [58] are the two most popular methods applied in CAMD [5]. These methods only require the estimation of molecular volumes and sigma profiles for the thermodynamic calculations. This makes the COSMO based approaches extremely suitable for the design of ionic liquids.

A preliminary design strategy to screen a list of possible ionic liquids for $\mathrm{CO}_{2}$ capture by using COSMO-RS was proposed by Farahipour et al. [59]. COSMO-RS was applied for activity coefficients estimation whereas viscosity and melting point constraints are modeled by employing GC models. The proposed methodology holds the capability to consider different trade-offs and optimal ionic liquids were identified by enumerating all possible cation and anion combinations. As a result, 10 ionic liquids with promising characteristics were identified out of a few thousand ionic liquid candidates considered. This method was improved with an extended model library for ionic liquid properties 
along with the consideration of several ionic liquid-based separation processes [60]. In their work, CAMD, property models based on GC, and process design simulations are combined and solved simultaneously to obtain the optimal ionic liquid separating agent. The developed method was then applied in case studies. For the first case study, $\mathrm{CO}_{2}$ capture from natural gas was considered while the focus of the second case study was ethanol-water azeotrope separation.

In recent years, systematic approaches have been developed for ionic liquid screening as extraction solvents. In one study, a sequential approach combining COSMO-RS-based LLE prediction, GC-based physical property prediction, and process simulation using Aspen Plus was applied [61]. Firstly, COSMO-RS is utilized to select the cation-anion solutions which possess desirable properties with common organic solvents as a benchmark. In the next step, GC tools have been applied to screen ionic liquid with desirable properties. Finally, ionic liquids that give the optimal process performance are selected by evaluation through process simulation. This method was then further improved by extending the UNIFAC-IL model to describe the extractive desulfurization of fuel oils system with extensive experimental data [62]. Optimal ionic liquid molecules for the extractive distillation can be identified by integrating both process and molecular design [63]. UNIFAC-IL model was selected for its database. The database fitting the group binary interaction parameters in the UNIFAC-IL model agreed well with the characteristics of the compounds in the system. An MINLP model was formulated to represent the design problem by combining UNIFAC-IL and GC models. The potential of the shortlisted ionic liquid candidates was then evaluated by process simulation. Song et al. [64] employed a similar approach for the design of ionic liquids for an alkane/cycloalkane extractive distillation process. In this design, the UNIFAC-IL model had been extended based on the consideration of the proximity effect in alkanes/cycloalkanes as distinct groups. Optimal ionic liquid as an entrainer had been modeled by formulating an MINLP problem and then through process simulation and economic analysis.

A CAMD approach was also applied to design optimal ionic liquids for cellulose dissolution. In this work, the solubility of cellulose in ionic liquids was estimated using a QSAR model which was developed using GC and ANN methods [65]. The design problem was formulated as a MINLP and solved by a genetic algorithm with an objective function maximizing the cellulose solubility in ionic liquids. Experimental analysis and characterization of the identified ionic liquid candidates were also performed. A simple method for CAMD in ionic liquids design as $\mathrm{CO}_{2}$ absorbents was proposed by Firaha et al. [66]. The strength of the interaction between $\mathrm{CO}_{2}$ and ionic liquid anions corresponded to chemical and physical absorption, respectively. The type of absorption was predicted according to geometry optimization accompanied by a solvation model. Solvated geometries provide Gibbs free energies which are analogous to the experimental values and correlate well with the experimentally observable absorption capacity.

An extensive GC model for infinite dilution activity coefficient (IDAC) of molecular solutes has been introduced to design ionic liquids for extractive desulfurization of gasoline [67]. In this work, ionic liquids are generated by applying purely empirical correlations of GC-based IDAC data and the least-squares support vector machine (LSSVM) method. The LSSVM-based model was capable of predicting IDACs based on the GCs of ions and Abraham's solvation descriptors of solutes. The reliability of the developed CAMD tool was verified by LLE simulation of ternary systems.

Another significant contribution is the ionic liquid design approach Karunanithi et al. [68] in which GC models and the COSMO-SAC thermodynamic model are combined to predict the surface charge density of ionic liquid structures predicted by density functional theory (DFT). The CAMD model can be solved via either deterministic or stochastic methods. This approach was tested on the design of ionic liquids for ibuprofen dissolution and ionic liquids with high electrical conductivity. The properties of the identified ionic liquid were verified with the data on the properties of the predicted structure. In another contribution, a multi-scale simulation approach was introduced to design ionic liquid solvents for separation processes [69]. An extended GC-COSMO approach was developed to estimate the $\sigma$-profiles and cavity volumes of ionic liquids. In this work, activity coefficients were 
predicted by applying the COSMO-SAC model while the rest of the properties were predicted using semi-empirical models. A CAMD problem was formulated using an MINLP model. The MINLP was then solved using the branch and bound approach in order to obtain the optimal ionic liquid solvents. A hybrid process design approach has been developed by Chen et al. [70]. This approach combined ionic liquid design and process simulation to obtain the best ionic liquid for hybrid process schemes. Hybrid schemes that satisfy the desired demands were generated. The ionic liquid design problem was solved based on the hybrid schemes generated, structural constraints, along with the physical properties. Shortlisted ionic liquid candidates were evaluated by conducting the simulation of the process.

The advances in the ML tools have also been utilized in the ionic liquid design. In a recent contribution, a huge data library of ionic liquids has been used to train ML models [71]. ML models were developed using three learning methods simultaneously, including the random forests (RF), cubist, and gradient boosted regression (GBM). The ML models thus developed (trained) were applied to design ionic liquids by identifying the cation-anion pairs from a large database that covers varied chemical scaffolds. The performance of the proposed method was then validated theoretically and experimentally. Over 2600 promising ionic liquids were found to be potential ionic liquids for gas separation and cellulose dissolution applications.

\section{Applications of PSE in Integrated Biorefineries}

In this section, an introduction to the field of integrated biorefineries and the types of integrated biorefineries is presented. The different types of processes common in an integrated biorefinery are explained. Following this discussion, various design approaches and major contributions made in each of these approaches are reviewed in detail. Finally, the research gaps are identified and major current challenges in the design and current work on these challenging areas are presented.

\subsection{Introduction to Integrated Biorefineries/Types of Integrated Biorefineries}

Over the past few decades, in order to enhance the sustainability of chemical and energy production, there has been a shift from petroleum-based feedstock to biomass-based feedstock. Besides, the societal realization of limited non-renewable resources, concerning environmental issues, technological advancements, and the discovery of additional renewable energy resources have also contributed to this shift [72].

Early on, biomass was mainly used as renewable resources for energy production. Later, biomass has also been used as feedstock for the production of value-added products via different processing pathways (physical, biological, and thermal, etc.). Various independent processes (e.g., gasification, pyrolysis, fermentation, hydrolysis, palletization, etc.) for the production of bio-chemicals, biomaterials, and bio-specialty chemicals from biomass have been developed. The utilization of biomass as feedstock for the production of multiple products through a biorefinery has also gained attention from both industry and the scientific community in the past decades [6]. A biorefinery was first defined as a complex system of sustainable, environmental, and resources-friendly technologies for the comprehensive utilization and the exploitation of biological raw materials (biomass) by Kamm et al. [73]. Similar to a petroleum refinery, a biorefinery utilizes different biomass resources as feedstock, combines a diversified collection of conversion pathways to produce a wide range of value-added products for example bioenergy, bulk chemicals, and fine chemicals. According to Frost and Draths [74], the application of the biorefinery concept plays a crucial role in driving the change in the chemical industry to shift from using petroleum-based feedstock to biomass-based feedstock. As biomass consists of a wide range of organic constituents, it comes in a variety of forms with different properties and characteristics. Therefore, various processing technologies can be applied to convert biomass into higher-value market products. A range of pre-treatment systems (such as size reduction, drying system, acid, and base hydrolysis) are needed to standardize biomass into a form that can be further converted into products. In order to maximize the quality and performance of the biorefinery, 
process integration and optimization shall be applied to synthesize a biorefinery comprised of multiple processing systems. This realization provides the foundation for the concept of integrated biorefinery which integrates various biomass conversion platforms [6].

According to Gravitis et al. [75], an integrated biorefinery represents a processing facility consisting of multiple technologies including feedstock handling, pretreatment processes, and different biomass conversion/upgrading processes. This allows the by-products and waste to be minimized while recovering the energy generated within the biorefinery. Therefore, the integrated biorefinery concept provides an opportunity to create a variety of value-added products while enhancing the sustainability performance in terms of the economic, environmental, and social impacts. A general representation of the integrated biorefinery concept is illustrated in Figure 1 as provided in the Introduction section.

As shown in Figure 1, an integrated biorefinery consists of different conversion pathways that convert different types of biomass feedstock into heat, power, and value-added products through depolymerizing and deoxygenating biomass components [76]. According to the U.S. Department of Energy/National Renewable Energy Laboratory (NREL), existing conversion pathways and technologies can be generally categorized into five different platforms based on the products produced [77]. These five platforms are the sugar platform, the thermochemical/syngas platform, the biogas platform, the carbon-rich chains platform, and the plant products platform. Table 2 summarizes the foci of these five biomass processing platforms as classified by NREL:

Table 2. Comparison of different biomass conversion platforms.

\begin{tabular}{ccc}
\hline Platform & Focus & Main Products \\
\hline Sugar & $\begin{array}{c}\text { Fermentation of sugars obtained via } \\
\text { extraction of biomass feedstocks }\end{array}$ & Ethanol and other building block chemicals \\
\hline Thermochemical syngas & Gasification of biomass feedstocks & Gaseous and liquid fuels \\
\hline Biogas & Decomposition of biomass feedstocks & Cooking gas \\
\hline Carbon-rich chains & $\begin{array}{c}\text { Transesterification of vegetable oil } \\
\text { or animal fat }\end{array}$ & Biodiesel (fatty acid methyl esters) \\
\hline Plant products & $\begin{array}{c}\text { Selective breeding and genetic } \\
\text { engineering of biological plant }\end{array}$ & $\begin{array}{c}\text { Plant strains that can be used as feedstock } \\
\text { for further conversion into chemicals and } \\
\text { compounds that are difficult to obtain } \\
\text { from plant naturally }\end{array}$ \\
\hline
\end{tabular}

Other than classifying the biomass conversion processes into different conversion platforms, these conversion processes and technologies are more commonly categorized according to the nature of the processes. Based on the method and nature of the processes, these conversion processes and technologies can be divided into four main groups of physical/mechanical, thermochemical, chemical, and biochemical/biological processes [76]. A detailed discussion of each group of technologies is covered in the following sub-sections.

\subsubsection{Physical/Mechanical Processes}

Physical/mechanical processes refer to processes that change the physical properties of the biomass, such as reduction of the size of the biomass material or separating biomass feedstock components without changing the state/composition. These processes are usually applied as pre-treatments in the early stages of a biorefinery to process the biomass feedstock into appropriate size ranges for subsequent conversion processes. Note that size reduction technologies refer to the physical treatment of biomass feedstock that includes cutting or commuting processes that result in changing of particle size, shape, and bulk density of the biomass. On the other hand, separation processes are used to separate the bulk biomass feedstock into its constituent components. Extraction methods can also be utilized as physical/mechanical processes to isolate valuable compounds from a bulk and inhomogeneous substrate [78]. 


\subsubsection{Thermochemical Processes}

Thermochemical processes are generally referred to as the decomposition of biomass into smaller molecules via thermal energy (i.e., gasification and pyrolysis, etc.). Gasification is a process that partially oxidizes biomass into syngas by keeping the biomass at a high temperature (above $700{ }^{\circ} \mathrm{C}$ ) [79]. Syngas is a gaseous mixture primarily consisting of carbon dioxide, carbon monoxide, hydrogen, methane, and water. It can be used directly as a stationary fuel or further converted into important intermediates such as methanol, ammonia, and oxyalcohols. Pyrolysis is a process that converts biomass into bio-oil, solid charcoal, and light gases similar to syngas in the absence of oxygen [80] and can generally be categorized as fast or slow pyrolysis. Fast pyrolysis normally operates at high heating rates with short vapor residence time (ranging from a few seconds to a few minutes) in the absence of oxygen. The typical operating temperature for fast pyrolysis is around $500^{\circ} \mathrm{C}$. Meanwhile, slow pyrolysis operates at a lower heating rate, longer vapor residence time, and a lower operating temperature at around $400{ }^{\circ} \mathrm{C}$. According to Brownsort [81], bio-oil and charcoal are the main products of fast pyrolysis and slow pyrolysis, respectively. Additionally, direct combustion is another type of thermochemical conversion process. Direct combustion of biomass involves the burning of biomass in an oxygen-rich environment to produce heat [82]. According to Demirbas [83], liquefaction of biomass into heavy oil is also considered a thermochemical process. In this process, biomass is reacted with carbon monoxide/hydrogen in the presence of sodium carbonate to form heavy oil.

\subsubsection{Chemical Processes}

Chemical processes refer to processes that change the chemical structure of biomass molecules at high temperature and pressure. Most of the time these chemical processes occur in the presence of a catalyst. Although chemical processes include a wide class of chemical reactions, the most common chemical processes to convert biomass into value-added products are hydrolysis and transesterification [76]. The hydrolysis process utilizes acids, alkalis, or enzymes to decompose molecules with complex molecular structures such as polysaccharides and proteins into their component sugars or derivative chemicals [84]. For example, hydrolysis depolymerizes cellulose into glucose while the derivative compound, levulinic acid can then be obtained from the resulting glucose. Transesterification is a chemical process that converts vegetable oils into biodiesel such as methyl esters and ethyl esters of fatty acids [85]. Fischer-Tropsch (FT) synthesis, steam reforming, and methanization are other common chemical processes for converting biomass into bio-chemicals.

\subsubsection{Biochemical/Biological Processes}

Biochemical/biological processes utilize biological enzymes or living organisms as biological catalysts to transform biomass into a commodity and specialty bio-chemicals. Compared to thermochemical and chemical processes which involve high temperatures and pressures, biochemical processes normally occur at lower temperatures and thus results in lower reaction rates [76]. Some established biochemical processes are anaerobic digestion and fermentation. Anaerobic digestion utilizes bacteria for the breakdown of biodegradable organic material in the absence of oxygen at a mild temperature $\left(30-65^{\circ} \mathrm{C}\right)$. The main product of anaerobic digestion is biogas, which is a mixture of methane, carbon dioxide, hydrogen sulfide, water, and other impurities. According to Romano and Zhang [86], the product biogas can be purified into more than $97 \%$ methane via different technologies (e.g., pressure swing adsorption, membrane, etc.), which can serve as a natural gas substitute. On the other hand, in the fermentation processes, the fermentable substrate is converted into different products such as alcohols or organic acids via enzymes or microorganisms [87].

\subsection{Synthesis and Design of Integrated Biorefineries}

To synthesize a sustainable integrated biorefinery with maximum performance and minimum environmental impact, it is essential to integrate different conversion technologies in a systematic 
and efficient manner. Process synthesis methods developed for conventional chemical processes can be extended to enable the synthesis of integrated biorefineries. Process synthesis is defined as the activity to identify the optimal interconnection of unit operations involved in the overall process and the optimal design and configuration of the units within the process [88]. According to Douglas [89], process synthesis can generally be classified into seven categories, i.e., synthesis of reaction pathway, synthesis of reactor network, synthesis of separation network, synthesis of mass exchange network, synthesis of material, synthesis of heat exchanger network, and synthesis of the complete flowsheet.

According to Kokossis and Yang [90], PSE approaches have the potential to support process synthesis and design, which can be applied and utilized in the design of integrated biorefineries. PSE is the field that covers the actions and activities involved in the engineering of systems consist of physical, chemical, and/or biological processing operations [91]. Throughout the years, various PSE approaches have been developed for the synthesis and design of integrated biorefineries [7,8,92], each with its own advantages and disadvantages. Some of the commonly used approaches are presented below.

\subsubsection{Hierarchical Approaches}

According to Douglas [93], hierarchical approaches use a series of decision-making processes and short-cut models at different hierarchical levels/stages for solving process synthesis problems. These approaches emphasize the decomposition of the problem and the screening of alternatives to identify the solution. According to Li and Kraslawski [94], hierarchical approaches generally offer a quick solution for process synthesis problems, however, they are not able to guarantee an optimal solution as they employ a sequential decomposition strategy. $\mathrm{Ng}$ et al. [95] proposed a hierarchical approach to synthesis and analysis of integrated biorefineries based on the Forward-Reverse Synthesis Tree concept. The proposed approach is a sequence of interlinked activities that utilize an appropriate level of information for the initial design. Later, Conde-Mejía et al. [96] applied a hierarchical design approach for the selection of processing routes in biorefinery facilities. Most recently, Tey et al. [97] further extended the developed hierarchical approach (commonly known as "Douglas' hierarchical approach") to the synthesis of an integrated biorefinery with consideration of the pretreatment system.

\subsubsection{Heuristic Searches}

According to Stephanopoulos and Westerberg [98], heuristic searches utilize engineering expertise to generate solutions for process synthesis problems. The first step is to identify a suitable base case design. This is followed by subsequent modification and fine-tuning to enhance the overall process performance. While heuristic searches are effective in providing feasible solutions for process synthesis problems, it is difficult for such methods to guarantee an optimal solution [99]. A heuristic framework for debottlenecking of a palm oil-based integrated biorefinery was presented by Kasivisvanathan et al. [100].

\subsubsection{Insight-Based Approaches}

Insight-based approaches such as pinch analysis, ternary diagrams, distillation residue curve maps, etc. have been developed for various applications in process flow sheeting. For example, Tay et al. [8] presented a graphical synthesis approach based on a carbon-hydrogen-oxygen ternary diagram, which enables tracking the change of atomic components within the process. Patel [101] presented a thermodynamic targeting approach based on Van Krevelen diagrams and energy balances for screening, evaluating, and comparing various biomass conversion processes. According to Voll [10], insight-based approaches enable visualization of process synthesis problems, however, employing such approaches in solving complicated process synthesis problems is prone to be restricted by the limited number of parameters and variables that can be considered. 


\subsubsection{Algorithmic Approaches}

Examples of algorithmic approaches include the process graph (P-graph) method. According to Oppenheim [102], algorithmic approaches execute a sequential set of actions based on automated reasoning, calculation, and data processing to determine solutions to process synthesis problems. Benjamin et al. [103] utilized the P-graph approach to generate alternative processes for an integrated biorefinery. As these approaches involve search space reduction, they are powerful and reliable to solve process synthesis problems related to process network synthesis, and often provide quick alternative solutions. However, algorithmic approaches are less flexible when applied to complicated process synthesis problems compared to mathematical optimization approaches [104]. Most recently, Yeo et al. [105] applied a graph-theoretic method to synthesize a sustainable biorefinery for the palm oil industry with optimum resources, which include fertilizer, steam, and electricity generation.

\subsubsection{Mathematical Optimization Approaches}

According to Grossmann [106], various mathematical optimization models (i.e., linear programming, mixed-integer linear programming, nonlinear programming, and mixed-integer nonlinear programming models) can be formulated to solve process synthesis problems. The models are then solved using different optimization techniques and/or commercial optimization software. Depending on the required information and the complexity/nature of the process synthesis problem, a range of mathematical programming models can be developed and solved to identify optimal solutions for various objectives. Bao et al. [107] presented a superstructure-based shortcut approach to track the feedstock to final products via chemical species for the synthesis of integrated biorefineries. Pham and El-Halwagi [108] presented a mathematical optimization model for integrated biorefineries based on the backward and forward synthesis concept. Later, various mathematical optimization models based on superstructure approaches have been developed for different configurations of integrated biorefineries; e.g., palm-based biorefinery [109], fast pyrolysis-gasification for production of liquid fuels and propylene [110], microalgal biorefinery [111], cyanobacteria biorefinery [112], seaweed-based biorefinery [113], etc. To further enhance the process performance in an integrated biorefinery, efforts have been devoted to the consideration of simultaneous reactor modeling, heating/cooling and work [114], simultaneous process synthesis, heat and power integration [115], production of biodiesel, hydrogen, and synthesis gas integrated with CHP [116], total site analysis [117]. Some studies have focused on retrofitting existing processes and integrating biorefinery technologies with such production facilities (e.g., palm oil industry [118], sago industry [119,120], pulp, and paper industry [121], etc.).

Additionally, many other alternative mathematical optimization methods such as value analysis [122], decomposition approach [9], disjunctive programming [123], modular optimization approach [124], fuzzy optimization [8,125], robust optimization [126], Monte Carlo type sampling [127], flexibility optimization [128], multi-objective optimization based on a genetic algorithm [129], multi-objective target-oriented robust optimization [130], etc. have been applied in synthesis and analysis of integrated biorefineries. Martín and Grossmann [131] reviewed alternative mathematical programming techniques for the design of sustainable biorefineries for the production of biofuels from different raw materials. While mathematical optimization approaches are useful and effective in solving process synthesis/design problems, such approaches may require intensive computational effort when rigorous process modeling is required [132].

\subsubsection{Hybrid Methods}

Hybrid methods that combine insights-based and mathematical optimization approaches have been developed to take advantage of the specific strengths of both approaches. An automated targeting method was developed to integrate the cascade approach into a mathematical optimization environment [133-135] for the synthesis of resource conservation networks. $\mathrm{Ng}$ [136] further developed the automated targeting method for the synthesis of integrated biorefineries by tracking carbon content 
from raw material (biomass) to final products. Tay and $\mathrm{Ng}$ [137] further extended the approach into a multiple-cascade automated targeting method for the synthesis of gasification based integrated biorefineries, where syngas composition is used as the quality measure of the gasification process. Finally, Shabbir et al. [138] combined a superstructure optimization approach with the automated targeting approach for the synthesis of integrated biorefineries with maximum economic performance and minimal environmental impact.

\subsection{Challenges in Designing Integrated Biorefineries}

While integrated biorefineries provide advantages as discussed in earlier sections, it should be noted that the unique features of integrated biorefineries make them less straightforward compared to conventional chemical processes. Due to the complex structure and varying compositions of biomass, the important thermodynamic properties (e.g., enthalpy, entropy, heat capacity, etc.) of biomass are often not well established. Besides, the rate of reaction for biomass conversion technologies such as fermentation, hydrolysis, etc. are difficult to determine accurately most of the time. Therefore, most of the available contributions in process synthesis for chemical processes cannot be directly applied for the synthesis of integrated biorefineries. Therefore, it is essential to develop systematic procedures to address the abovementioned issues. In order to synthesize and design a sustainable integrated biorefinery, the following criteria shall be fulfilled $[139,140]$ :

i Able to minimize energy consumption and potential environmental impact through material and energy integrations between different conversion platforms.

ii Able to accommodate the varying seasonal patterns on feedstock availability and quality through integration of different biomass conversion platforms.

iii Able to depolymerize biomass components to intermediate products that match the requirements of subsequent processing technologies.

iv Able to maximize the yield and quality of value-added products.

Identifying new potential product molecules from a given biomass feedstock can be achieved through reaction pathway approaches. Andiappan et al. [141] presented a reaction pathway synthesis approach for integrated biorefineries with consideration of economic, energy assessment, and environmental impact in terms of incremental burden. Most recently, Tey et al. [142] further extended the chemical reaction pathway map to synthesize a sustainable integrated biorefinery for the production of fine chemicals from palm-based biomass. Additionally, Madenoor Ramapriya et al. (2018) extended the usage of the superstructure approach for integrated biorefineries synthesis with consideration of complex reaction networks. Similarly, Filho et al. [143] presented an integrated biorefinery for bioethanol production with an analysis of the molecular transformations.

Design of integrated biorefineries requires the ability to handle process/market uncertainties while maintaining the process performance. Tang et al. [144] presented a superstructure optimization approach for the synthesis of integrated biorefineries with consideration of biomass feedstock, value-added products, trenda of market price, constraints of technology, and system uncertainties at multi-periods. Later, Tay et al. [145] presented a mathematical optimization model for the synthesis of integrated biorefineries with supply and demand uncertainties based on a robust optimization approach. Moreover, a framework that uses a superstructure-based process synthesis approach integrated with uncertainty analysis was developed to consider price effects on the design of an integrated biorefinery [146]. To address the effect of changing biomass type and composition in a multi-product biorefinery, Giuliano et al. [147] presented a MINLP to synthesize an integrated biorefinery that converts lignocellulosic biomass into levulinic acid, succinic acid, and ethanol. Meanwhile, Čuček et al. [148] developed a multi-period optimization approach for a heat-integrated biorefinery's supply network with maximum economic performance. Additionally, the biomass supply chain also impacts the overall performance of the integrated biorefinery. In order to address such uncertainties, a two-stage optimization approach (macro- and micro-stage) has been presented. 
The micro-stage involves waste (biomass, industrial waste, etc.) optimization and allocation, as well as the design of the integrated biorefinery, while the macro-stage focuses on supply chain network synthesis and optimization. Various review papers on biomass supply chains covering different aspects (e.g., uncertainties and sustainability [149]; value chain optimization [150]; economic, social and environmental perspectives [151]; design and management [152]; modeling and optimization [153]; techno-economic modeling and optimization [154] have been presented in the literature. Stewart and El-Halwagi [155] provided a detailed review and analysis of the integration of biorefinery innovations into existing processes. This book also covers the application of PSE tools in various stages of the design of such processes, biorefinery products, supply chains, policies, and environmental impacts. Most recently, Lo et al. [156] provided a state-of-the-art review of techno-economic analysis for biomass supply chains.

In addition to the synthesis of independent integrated biorefineries and supply chain networks, the synthesis of industrial symbiosis for bioenergy networks has also received much interest from the research community. $\mathrm{Ng}$ et al. [157] developed a superstructure model for the synthesis of palm-based biorefineries, which considers multiple owners in an industrial symbiosis network. Later, $\mathrm{Ng}$ et al. [158] presented a superstructure-based disjunctive fuzzy optimization approach for planning and synthesis of industrial symbiosis in bioenergy systems. More recently, Barla et al. [159] applied circular economy concepts in the design of a textile waste biorefinery.

\section{Application of Molecular Design within the Context of Integrated Biorefineries}

As presented in the previous section, the products produced from integrated biorefineries are generally classified into two major categories of chemical/material products and energy products [76]. Examples of energy products include biogas, bio-oil, biodiesel, etc. which are products that are utilized based on their energy content. These products are commonly used for the generation of heat, electricity, and energy for different electrification and transportation purposes. On the other hand, chemical/material products are often utilized based on different functionalities given by their physical and chemical properties. Carbohydrates are identified as one of the commonly utilized biomass feedstocks for the production of commodity chemicals and specialty chemicals [72]. According to Lichtenthaler and Mondel [160], the primary form of carbohydrates is in the form of polysaccharides (which are also known as starch). Traditionally, starch (polysaccharide) and its derivative D-glucose (monosaccharide) have been greatly utilized as raw material to produce commodity chemicals and polymers by chemical industries [161]. As starch is an important food resource, utilization of starch to produce chemical products has raised a lot of concerns from the community on the competition of starch utilization between food and industrial applications. For this reason, the utilization of lignocellulosic biomass to produce biochemical products has been receiving focus and attraction as lignocellulosic biomass is mostly plant-based waste in different forms [72]. According to Wyman [162], lignocellulosic biomass is made up of primarily cellulose, hemicellulose, and lignin. Lignocellulosic biomass can be converted into different value-added products via different conversion technologies. Moreover, lignocellulosic biomass can be converted into different intermediate products with a high content of hydroxyl groups through the liquefaction process [163].

In view of the possibility of lignocellulosic biomass conversion into different value-added chemical products, extensive effort has been invested by industrial and research sectors to identify these value-added chemical products. Elliott [164] conducted a study on potential chemical products that can be produced from biomass, based on different biomass conversion. According to Elliot [164], the potential chemical products can be commonly classified into fermentation products, gasification products, catalytic/bioprocessing products, derivatives of carbohydrates, and derivatives of plants. Later, findings on the identification of twelve chemical building blocks that are possible to be converted from starch through different processing technologies are presented by Werpy and Peterson [165]. There exists a potential for these twelve building blocks to be further converted into new families of useful chemical molecules. Hence, these twelve building blocks provide the 
potential to be utilized to produce different bio-based chemical products that fulfill market needs. In addition, Holladay et al. [166] presented their study on the potential of lignin recovery to produce macromolecules, aromatics, and miscellaneous monomers. These potential products include different fuel additives, adhesives, carbon fiber, etc. Skibar et al. [167] emphasized the future of biomass through their discussion on the efforts of the chemical industry in utilizing biomass to produce value-added products. In addition to the traditional usage of biomass to produce polymers, the future of biomass lies in the production of specialty products as biomass has the potential to be utilized in producing specialty chemicals such as pharmaceutical, beauty, and personal care products [167]. From the works discussed above, it is obvious that the future of biomass utilization covers the production of energy products, bulk chemical products, and new and novel products such as fine and specialty chemical products. In most cases, such products are designed to satisfy product needs [168]. Thus, the product design aspects have to be taken into account while synthesizing an optimally integrated biorefinery to make sure that the products produced by integrated biorefinery meet the required product needs. This goal can be fulfilled by integrating the synthesis of integrated biorefineries with chemical product design.

Chemical product design problems are suitable to be explained as a process to search for chemical products that fulfill preferred product needs. Traditionally, the product designers first hypothesize a target molecule that has the preferred product needs while designing a chemical product. The subsequent step would be the product synthesis step, which is followed soon by the product testing step to test for the preferred product needs. Target molecule revision and redesign are required repeated if the target molecule does not satisfy the preferred product needs. Hence, it can be seen that the traditional approaches of chemical product design require an iterative process, which leads them to being inefficient, laborious, and low in cost-effectiveness [169]. In light of these limitations, CAMD techniques provide efficient and effective options for the design of chemical products.

In the past decades, CAMD techniques have been gaining attraction and appeared as reliable techniques for their capability in identifying feasible molecules that possess the desired set of product needs [170]. This includes the integration of CAMD techniques with process synthesis for the consideration of product design aspects while synthesizing integrated biorefineries. Hechinger et al. (2010) [171] prosed an integrated approach to the design of biofuels by combining product and process design aspects. The presented study designs biofuels in terms of their molecular structure by using CAMD techniques and identify alternative conversion pathways for the production of biofuels by applying reaction network flux analysis. $\mathrm{Ng}$ et al. b [172] proposed an integrated optimization approach for the design of optimal chemical products and synthesis of optimal biomass processing pathways in integrated biorefineries. The optimal biochemical products are designed using CAMD techniques while optimum biomass processing pathways are identified through the developed mathematical superstructure optimization approach. Later, $\mathrm{Ng}$ et al. b [173] extended the integrated optimization approach for the design of optimal mixture and synthesis of optimal processing pathways in an integrated biorefinery. Later, Bertran et al. [174] presented two special tools which include a database that employs specially developed knowledge to represent the processing system, and Super-O, which is a software with a practical user interface to guide users for the synthesis of molecular product and integrated biorefinery.

\subsection{Integrated Tools for Ionic Liquid Design within Integrated Biorefineries}

The availability of huge data libraries and property prediction models along with the general improvements in computational tools has enabled the application of ionic liquids in the chemical process industry. One of the early applications of the CAMD approach for an integrated process is the design of ionic liquid via the CAMD approach for the purification of bioethanol [175]. CAMD is used to design ionic liquids that can be used to produce $99 \%$ pure ethanol from bioethanol with an ethanol concentration of $85 \%$. Various GC models have been used to predict the properties and activity coefficients required to estimate/predict vapor-liquid equilibria. 
An extended CAMD approach for carbon capture was developed by Chong et al. [176] to model task-specific ionic liquids. In this work, optimal ionic liquid candidates and conditions for the carbon capture process were determined simultaneously by considering the effect of process conditions as part of the developed approach. To reduce the search space, continuous variables of operating conditions are discretized by introducing disjunctive programming. The thermophysical properties of ionic liquids are predicted using an extended UNIFAC model. To ensure the feasibility of the synthesized ionic liquids, appropriate structural constraints, including cation-anion pairing constraints are included in the design.

In another effort, optimal ionic liquid candidates were screened using the COSMO-RS model, absorption mechanisms, and experimental data for the decarbonization of shale gas [177]. In addition to the Henry's constant, viscosity and toxicity of the ionic liquids are considered in the screening of candidates. Thermodynamic property models, physicochemical properties, and phase equilibria related to the decarbonization process were established. The new ionic liquid-based decarbonization technology was then evaluated by process simulation. Simulations confirmed that the use of ionic liquid requires less energy than the conventional methyl diethanolamine (MDEA) process for $\mathrm{CO}_{2}$ capture.

Chong et al. [178] presented a comprehensive study, where the ionic liquid design was integrated with the entire bioenergy production system that produces multiple energy products from biomass. In this work, ionic liquid is used to remove $\mathrm{CO}_{2}$ from a bioenergy production plant. This process is a bioenergy with carbon capture and storage (BECCS) system. Since the production of bioenergy is considered to be carbon neutral, the $\mathrm{CO}_{2}$ removal and storage make this a negative emission process. One of the challenges in this design was identifying the optimal conditions for bioenergy production and for $\mathrm{CO}_{2}$ removal. Therefore, the bioenergy production system was retrofitted to provide utilities for the carbon capture system.

Liu et al. [179] applied a CAMD approach to screen and predict ionic liquid candidates for shale gas separation. In this work, an extensive ionic liquid-database was established for various gas-ionic liquid systems which consisted of the solubility data of gases in several ionic liquids. Henry's law constants have also been established for several combinations of gases and ionic liquids. A corrected COSMO-RS model was developed to generate pseudo-experimental data after validation to model the systems for which no experimental data were available. A UNIFAC-IL method was established to predict the solubility of shale gas components in ionic liquids. The model showed good agreement between the predictions and experimental solubility data.

Ionic liquids have also been introduced as suitable solvents for the recovery of bioisoprene, which is a promising alternative to petroleum-derived isoprene [180]. In this work, CAILD and UNIFAC-IL models are applied for the thermodynamic calculations and GC based methods are used for the prediction of physical properties. The thermodynamic behavior of the bioisoprene systems involving ionic liquids was described using the extended UNIFAC-IL model that combines gas-organic chemicals using extensive experimental data from literature and pseudo-experimental data from COSMO-RS calculations. The final verification of the process improvements with the designed ionic liquid has been performed via a detailed simulation of the process.

To design ionic liquid for absorbents, the Absorption-Selectivity-Desorption index (ASDI) has been integrated with CAMD tools for ionic liquid design [181]. Thermodynamic properties of ionic liquids are predicted by the COSMO-GC-IL integrated with the COSMO-SAC model. The ionic liquid design was formulated as an optimization problem where the rest of the physical properties were modeled using GC models. A case study has been performed on sour gas absorption in a syngas production process. The integrated ASDI was shown to be capable of determining promising ionic liquid absorbents that can meet the thermodynamic property targets while maintaining low energy consumption for the process. 


\subsection{Opportunities for Further Research}

\subsubsection{Expanding the Optimization Scope/Parameters for Integrated Biorefinery Design}

The above-detailed review of existing synthesis/optimization approaches for integrated biorefineries has discussed various approaches ranging from insights-based approaches to complex mathematical optimization models. The developed approaches can address steady-state processes, batch processes, as well as process and market uncertainties. In order to incorporate a sustainable integrated biorefinery, global life cycle optimization ought to be applied during the synthesis stage. The Life Cycle Optimization approach [182] can be extended for concurrent synthesis and optimization of sustainable integrated biorefineries with consideration of economic, environmental, and societal factors/impacts. It is noted that most of the above-mentioned methods focus on technical feasibility, environmental sustainability, market uncertainties, etc. However, there is limited consideration of societal impacts during the design/development of the integrated biorefinery. Therefore, society impacts should be taken into consideration in future efforts.

It should also be noted that a lot of research and development activities are moving towards human-centered design approaches; which is an approach to problem-solving that incorporates the human perspective in all steps. Human-centered design [183] is generally applied in design and management frameworks to solve problems with developed solutions. In order to consider human perspectives in the synthesis and analysis of integrated biorefineries, integration of the human-centered design methodology into PSE approaches would need to be developed.

\subsubsection{Design of Novel Ionic Liquids}

As discussed in earlier sections, most property prediction models are only applicable for commonly studied ionic liquids such as pyrrolidinium-, ammonium-, imidazolium-, phosphonium- and pyridinium-based ionic liquids, which hinder the discovery of potential new ionic liquids using CAMD tools. Future directions should focus on developing property prediction models that are able to estimate properties for a wider range of pure ionic liquids and/or ionic liquid mixtures. This shortcoming may be addressed by predicting properties of ionic liquids based on functional groups rather than ionic liquid constituents. Accurate correlation equations are key to ensuring that the results generated by process/product design methods/tools are reliable. In addition, there are several works conducted on the effect of solvents on reaction rates. However, no such studies have been conducted on the influence of ionic liquid solvents on reactions. Therefore, it is worth exploring the application of quantum mechanical calculations to predict the rate constants of reactions in various ionic liquid media. Another new class of solvents called deep eutectic solvents (DESs) have received much attention in recent years as they are relatively cheap, simple to synthesize, and have good biodegradability [184]. DESs are solvents that comprise both hydrogen bond acceptors and donors. Some researchers have validated their feasibility as entrainers in the separation of azeotropic mixtures through experiments. With the use of DESs as entrainers in the ethanol-water azeotropic system, the relative volatility of the ethanol-water system increased 4.7 times compared to the DES-free system [185]. Despite the potential of these materials, studies on modeling extractive distillation processes using DESs as entrainers remain limited. This may be due to the fact that there is very limited thermophysical property data available, as this particular research field is still relatively new. A general model that requires only critical pressure, temperature, and one reference viscosity point has been developed to predict the viscosities of DESs [186]. However, there is still a need to improve the model accuracy and develop more property prediction models for DESs to facilitate the computational design and/or screening of solvents.

\section{Conclusions}

Recent advances in the development of computational PSE tools have enabled the design of ionic liquids and the design of integrated biorefineries. It is imperative that ionic liquids may serve 
as potential replacements for current organic solvents when considering stringent environmental regulations and the implementation of a clean manufacturing practice. Nevertheless, the process of identifying an optimal ionic liquid through experimentation is a very tedious task as a very large number of possible ionic liquid combinations exist. Various PSE approaches have been developed in order to make an optimal selection of ionic liquids prior to experimental testing. Similarly, numerous research works have been performed to optimize the synthesis and design of sustainable integrated biorefineries with maximum performance and minimal environmental impact. The application of existing PSE tools to these problems had been extremely challenging because of the difficulty in incorporating accurate property prediction tools in the design of ionic liquids and the computational challenges in the design of such a large and complex processing facility. Decomposition-based approaches developed by different researchers have been instrumental in reducing the complexity of these design problems.

Author Contributions: Conceptualization, N.G.C. and D.K.S.N.; Methodology, L.Y.N. and J.O.; Software, validation, formal analysis, J.W.C.; Investigation, resources, data curation; N.G.C. and D.K.S.N.; writing- original draft preparation, L.Y.N. and J.O.; Writing-review and editing, M.R.E.; visualization, J.W.C.; supervision, N.G.C. and D.K.S.N.; project administration-N.G.C. and M.R.E.; funding acquisition, N.G.C. All authors have read and agreed to the published version of the manuscript.

Funding: This research was funded by the Ministry of Higher Education, Malaysia, Grant number FRGS/1/2019/TK02/UNIM/02/1.

Conflicts of Interest: The authors declare no conflict of interest.

\section{Nomenclature}

\begin{tabular}{|c|c|}
\hline [4bmpy][TCM] & 1-butyl-4-methylpyridinium tricyanomethanide \\
\hline$[\mathrm{Bim}]\left[\mathrm{NTf}_{2}\right]$ & 1-butyl imidazolium bis(trifluoromethylsulfonyl)imide \\
\hline [BMim] $[\mathrm{Cl}]$ & 1-butyl-3-methylimidazolium chloride \\
\hline [BMIM][OAc] & 1-butyl-3-methylimidazolium acetate \\
\hline$[\mathrm{Bmim}]_{2}\left[\mathrm{CuCl}_{4}\right]$ & Bis(1-butyl-3-methyl imidazolium) copper tetrachloride salt \\
\hline$[\mathrm{Bmim}]_{2}\left[\mathrm{SnCl}_{4}\right]$ & Bis(1-butyl-3-methyl imidazolium) stannum tetrachloride salt \\
\hline [EMIM][MS] & 1-Ethyl-3-methylimidazolium methyl sulfate \\
\hline [Emim]Ac & 1-Ethyl-3-methylimidazolium acetate \\
\hline$[\mathrm{EMIM}] \mathrm{Cl}$ & 1-methylimidazolium chloride \\
\hline$[\mathrm{NH} 2 \mathrm{p}-\mathrm{bim}]\left[\mathrm{BF}_{4}\right]$ & 1-butyl-3-propylamineimidazolium tetrafluoroborate \\
\hline $\mathrm{BMIM} \mathrm{BF}_{4}$ & 1-butyl-3-methylimidazolium hexafluorophosphate \\
\hline $\mathrm{C}_{9} \mathrm{H}_{14} \mathrm{NBF}_{4}$ & 1-butylpyridinium tetrafluoroborate \\
\hline $\mathrm{CO}_{2}$ & Carbon dioxide \\
\hline EAN & Ethyl ammonium nitrate \\
\hline $\mathrm{H}_{2} \mathrm{~S}$ & Hydrogen sulfide \\
\hline $\mathrm{NH}_{3}$ & Ammonia \\
\hline $\mathrm{SO}_{2}$ & Sulfur dioxide \\
\hline
\end{tabular}

\section{Abbreviations}

$\begin{array}{ll}\text { ANN } & \text { Artificial neural networks } \\ \text { ASDI } & \text { Absorption selectivity desorption index } \\ \text { CAILD } & \text { Computer-aided ionic liquid design } \\ \text { CAMD } & \text { Computer-aided molecular design } \\ \text { CHP } & \text { Combined heat and power } \\ \text { COSMO } & \text { Conductor-like screening model } \\ \text { COSMO-RS } & \text { COSMO for real solvents } \\ \text { COSMO-SAC } & \text { COSMO for segment activity coefficient } \\ \text { DES } & \text { Deep eutectic solvent } \\ \text { DFT } & \text { Density functional theory } \\ \text { EOS } & \text { Equations of state }\end{array}$




$\begin{array}{ll}\text { FT } & \text { Fischer-Tropsch } \\ \text { GBM } & \text { Gradient boosted regression } \\ \text { GC } & \text { Group contribution } \\ \text { GC-COSMO } & \text { Group contribution-based COSMO } \\ \text { IDAC } & \text { Infinite dilution activity coefficient } \\ \text { IL } & \text { Ionic liquid } \\ \text { LCA } & \text { Life cycle assessment } \\ \text { LLE } & \text { Liquid-liquid extraction } \\ \text { LSSVM } & \text { Least-squared support vector machine } \\ \text { MC } & \text { Monte Carlo simulations } \\ \text { MD } & \text { Molecular dynamics simulations } \\ \text { MILP } & \text { Mixed-integer linear program } \\ \text { MINLP } & \text { Mixed-integer nonlinear program } \\ \text { ML } & \text { Machine learning } \\ \text { PPMV } & \text { Parts per million volume } \\ \text { PSE } & \text { Process systems engineering } \\ \text { QM } & \text { Quantum mechanics } \\ \text { QSAR } & \text { Quantitative structure-activity relationship } \\ \text { QSPR } & \text { Quantitative structure-property relationship } \\ \text { RF } & \text { Random forests } \\ \text { RHST } & \text { Rough hard-sphere theory } \\ \text { UNIFAC } & \text { Universal quasichemical functional-group activity coefficients } \\ \text { ZIF } & \text { Zeolitic imidazolate framework }\end{array}$

\section{References}

1. Grossmann, I.E.; Westerberg, A.W. Research challenges in process systems engineering. AIChE J. 2000, 46, 1700-1703. [CrossRef]

2. Grossmann, I.E. Challenges in the new millennium: Product discovery and design, enterprise and supply chain optimization, global life cycle assessment. Comput. Aided Chem. Eng. 2004, 29, 29-39. [CrossRef]

3. Chen, Y.; Kontogeorgis, G.M.; Woodley, J.M. Group Contribution Based Estimation Method for Properties of Ionic Liquids. Ind. Eng. Chem. Res. 2019, 58, 4277-4292. [CrossRef]

4. Karunanithi, A.T.; Mehrkesh, A. Computer-aided design of tailor-made ionic liquids. AIChE J. 2013, 59, 4627-4640. [CrossRef]

5. Austin, N.D.; Sahinidis, N.V.; Trahan, D.W. A COSMO-based approach to computer-aided mixture design. Chem. Eng. Sci. 2017, 159, 93-105. [CrossRef]

6. Fernando, S.; Adhikari, S.; Chandrapal, C.; Murali, N. Biorefineries: Current Status, Challenges, and Future Direction. Energy Fuels 2006, 20, 1727-1737. [CrossRef]

7. Sammons, N.E.; Yuan, W.; Eden, M.R.; Aksoy, B.; Cullinan, H.T. Optimal biorefinery product allocation by combining process and economic modeling. Chem. Eng. Res. Des. 2008, 86, 800-808. [CrossRef]

8. Tay, D.H.S.; Ng, D.K.; Sammons, N.E.; Eden, M.R. Fuzzy Optimization Approach for the Synthesis of a Sustainable Integrated Biorefinery. Ind. Eng. Chem. Res. 2011, 50, 1652-1665. [CrossRef]

9. Kokossis, A.; Tsakalova, M.; Pyrgakis, K. Design of integrated biorefineries. Comput. Chem. Eng. 2015, 81, 40-56. [CrossRef]

10. Voll, P. Automated Optimization-Based Synthesis of Distributed Energy Supply Systems; RWTH Aachen University: Aachen, Germany, 2013.

11. Walden, P. Molecular weights and electrical conductivity of several fused salts. Bull. Acad. Imp. Sci. 1914, 1800, 405-422.

12. Bates, E.D.; Mayton, R.D.; Ntai, I.; Davis, J.H. $\mathrm{CO}_{2}$ Capture by a Task-Specific Ionic Liquid. J. Am. Chem. Soc. 2002, 124, 926-927. [CrossRef] [PubMed]

13. Marsh, K.N.; Boxall, J.A.; Lichtenthaler, R. Room temperature ionic liquids and their mixtures-A review. Fluid Phase Equilib. 2004, 219, 93-98. [CrossRef]

14. Olivier-Bourbigou, H.; Magna, L.; Morvan, D. Ionic liquids and catalysis: Recent progress from knowledge to applications. Appl. Catal. A Gen. 2010, 373, 1-56. [CrossRef] 
15. Eftekhari, A. Supercapacitors utilising ionic liquids. Energy Storage Mater. 2017, 9, 47-69. [CrossRef]

16. Morton, M.D.; Hamer, C.K. Ionic liquids-The beginning of the end or the end of the beginning? A look at the life of ionic liquids through patent claims. Sep. Purif. Technol. 2018, 196, 3-9. [CrossRef]

17. Lei, Z.; Chen, B.; Koo, Y.-M.; Macfarlane, D.R. Introduction: Ionic Liquids. Chem. Rev. 2017, 117, $6633-6635$. [CrossRef]

18. Freemantle, M. Chemistry Basf's Smart Ionic Liquid. Chem. Eng. News Arch. 2003, 81, 9. [CrossRef]

19. Kazemi, S.; Nor, M.I.M.; Teoh, W.H. Thermodynamic and economic investigation of an ionic liquid as a new proposed geothermal fluid in different organic Rankine cycles for energy production. Energy 2020, 193, 116722. [CrossRef]

20. Kermani, N.A.; Petrushina, I.; Rokni, M. Evaluation of ionic liquids as replacements for the solid piston in conventional hydrogen reciprocating compressors: A review. Int. J. Hydrogen Energy 2020, 45, 16337-16354. [CrossRef]

21. Bian, J.; Peng, F.; Peng, X.-P.; Xiao, X.; Peng, P.; Xu, F.; Sun, R.-C. Effect of [Emim]Ac pretreatment on the structure and enzymatic hydrolysis of sugarcane bagasse cellulose. Carbohydr. Polym. 2014, 100, 211-217. [CrossRef]

22. Khan, A.S.; Man, Z.; Bustam, M.A.; Kait, C.F.; Ullah, Z.; Nasrullah, A.; Khan, M.I.; Gonfa, G.; Ahmad, P.; Muhammad, N. Kinetics and thermodynamic parameters of ionic liquid pretreated rubber wood biomass. J. Mol. Liq. 2016, 223, 754-762. [CrossRef]

23. Szalaty, T.J.; Klapiszewski, Ł.; Kurc, B.; Skrzypczak, A.; Jesionowski, T. A comparison of protic and aprotic ionic liquids as effective activating agents of kraft lignin. Developing functional $\mathrm{MnO}_{2} /$ lignin hybrid materials. J. Mol. Liq. 2018, 261, 456-467. [CrossRef]

24. Zuo, L.; Ao, X.; Guo, Y. Study on the synthesis of dual-chain ionic liquids and their application in the extraction of flavonoids. J. Chromatogr. A 2020, 1628, 461446. [CrossRef]

25. Wang, Y.-X.; Cao, X.-J. Extracting keratin from chicken feathers by using a hydrophobic ionic liquid. Process. Biochem. 2012, 47, 896-899. [CrossRef]

26. Zhu, Z.; Ri, Y.; Jia, H.; Li, X.; Wang, Y.; Wang, Y. Process evaluation on the separation of ethyl acetate and ethanol using extractive distillation with ionic liquid. Sep. Purif. Technol. 2017, 181, 44-52. [CrossRef]

27. Ayuso, M.; Cañada-Barcala, A.; Larriba, M.; Navarro, P.; Delgado-Mellado, N.; García, J.; Rodríguez, F. Enhanced separation of benzene and cyclohexane by homogeneous extractive distillation using ionic liquids as entrainers. Sep. Purif. Technol. 2020, 240, 116583. [CrossRef]

28. Bhattacharya, M.; Mandal, M.K. Synthesis and characterization of ionic liquid based mixed matrix membrane for acid gas separation. J. Clean. Prod. 2017, 156, 174-183. [CrossRef]

29. Lei, Z.; Dai, C.; Song, W. Adsorptive absorption: A preliminary experimental and modeling study on $\mathrm{CO}_{2}$ solubility. Chem. Eng. Sci. 2015, 127, 260-268. [CrossRef]

30. Blanchard, L.A.; Hancu, D.; Beckman, E.J.; Brennecke, J.F. Green processing using ionic liquids and $\mathrm{CO}_{2}$. Nature 1999, 399, 28-29. [CrossRef]

31. Xu, Q.; Jiang, W.; Xiao, J.; Wei, X.-H. Absorption of Sulfur Dioxide by Tetraglyme-Sodium Salt Ionic Liquid. Mol. 2019, 24, 436. [CrossRef]

32. Shang, D.; Zhang, S.; Zeng, S.; Jiang, K.; Gao, H.; Dong, H.; Yang, Q.; Zhang, S. Protic ionic liquid [Bim][NTf2] with strong hydrogen bond donating ability for highly efficient ammonia absorption. Green Chem. 2017, 19, 937-945. [CrossRef]

33. Wang, J.; Zeng, S.; Huo, F.; Shang, D.; He, H.; Bai, L.; Zhang, X.; Li, J. Metal chloride anion-based ionic liquids for efficient separation of $\mathrm{NH}_{3}$. J. Clean. Prod. 2019, 206, 661-669. [CrossRef]

34. Brennecke, J.F.; Maginn, E.J. Ionic liquids: Innovative fluids for chemical processing. AIChE J. 2001, 47, 2384-2389. [CrossRef]

35. Fan, Y.; Dong, X.; Zhong, Y.; Li, J.; Miao, J.; Hua, S.; Li, Y.; Cheng, B.; Chen, W. Effects of ionic liquids on the hydrolysis of casein by lumbrokinase. Biochem. Eng. J. 2016, 109, 35-42. [CrossRef]

36. Franca, J.M.P.; De Castro, C.A.N.; Lopes, M.M.; Nunes, V.M.B. Influence of Thermophysical Properties of Ionic Liquids in Chemical Process Design. J. Chem. Eng. Data 2009, 54, 2569-2575.

37. Predel, T.; Schlücker, E. Ionic Liquids in Oxygen Compression. Chem. Eng. Technol. 2009, 32, 1183-1188. [CrossRef]

38. Nasirpour, N.; Mohammadpourfard, M.; Heris, S. Ionic liquids: Promising compounds for sustainable chemical processes and applications. Chem. Eng. Res. Des. 2020, 160, 264-300. [CrossRef] 
39. Bogdanov, M.G.; Svinyarov, I. Ionic liquid-supported solid-liquid extraction of bioactive alkaloids. II. Kinetics, modeling and mechanism of glaucine extraction from Glaucium flavum Cr. (Papaveraceae). Sep. Purif. Technol. 2013, 103, 279-288. [CrossRef]

40. Seiler, M.; Jork, C.; Kavarnou, A.; Arlt, W.; Hirsch, R. Separation of azeotropic mixtures using hyperbranched polymers or ionic liquids. AIChE J. 2004, 50, 2439-2454. [CrossRef]

41. Boli, E.; Voutsas, E. Ionic liquids as entrainers for the separation of azeotropic mixtures: Experimental measurements and COSMO-RS predictions. Chem. Eng. Sci. 2020, 219, 115579. [CrossRef]

42. Fadeev, A.G.; Meagher, M.M. Opportunities for ionic liquids in recovery of biofuels. Chem. Commun. 2001, 3, 295-296. [CrossRef]

43. Anthony, J.L.; Maginn, A.E.J.; Brennecke, J.F. Solution Thermodynamics of Imidazolium-Based Ionic Liquids and Water. J. Phys. Chem. B 2001, 105, 10942-10949. [CrossRef]

44. Anthony, J.L.; Maginn, E.J.; Brennecke, J.F. Gas Solubilities in 1-n-Butyl-3-methylimidazolium Hexafluorophosphate. ACS Symp. Ser. 2002, 818, 260-269.

45. Xue, Z.; Zhang, Z.; Han, J.; Chen, Y.; Mu, T. Carbon dioxide capture by a dual amino ionic liquid with amino-functionalized imidazolium cation and taurine anion. Int. J. Greenh. Control. 2011, 5, 628-633. [CrossRef]

46. Chen, H.; He, Y.; Zhu, J.; Alias, H.; Ding, Y.; Nancarrow, P.; Hardacre, C.; Rooney, D.W.; Tan, C. Rheological and heat transfer behaviour of the ionic liquid, [C4mim] [NTf2]. Int. J. Heat Fluid Flow 2008, 29, 149-155. [CrossRef]

47. Dong, Q.; Muzny, C.D.; Kazakov, A.; Diky, V.; Magee, J.W.; Widegren, J.A.; Chirico, R.D.; Marsh, K.N.; Frenkel, M. ILThermo: A Free-Access Web Database for Thermodynamic Properties of Ionic Liquids. J. Chem. Eng. Data 2007, 52, 1151-1159. [CrossRef]

48. Hosseini, S.M.; Mulero, A.; Alavianmehr, M.M. Predictive methods and semi-classical Equations of State for pure ionic liquids: A review. J. Chem. Thermodyn. 2019, 130, 47-94. [CrossRef]

49. Coutinho, J.A.P.; Carvalho, P.J.; Oliveira, N.M. Predictive methods for the estimation of thermophysical properties of ionic liquids. RSC Adv. 2012, 2, 7322-7346. [CrossRef]

50. Torrecilla, J.S.; García, J.; Rojo, E.; Rodríguez, F. Estimation of toxicity of ionic liquids in Leukemia Rat Cell Line and Acetylcholinesterase enzyme by principal component analysis, neural networks and multiple lineal regressions. J. Hazard. Mater. 2009, 164, 182-194. [CrossRef]

51. Abramenko, N.; Kustov, L.M.; Metelytsia, L.; Kovalishyn, V.; Tetko, I.; Peijnenburg, W. A review of recent advances towards the development of QSAR models for toxicity assessment of ionic liquids. J. Hazard. Mater. 2020, 384, 121429. [CrossRef]

52. Taghizadehfard, M.; Hosseini, S.M.; Pierantozzi, M.; Alavianmehr, M.M. Predicting the volumetric properties of pure and mixture of amino acid-based ionic liquids. J. Mol. Liq. 2019, 294, 111604. [CrossRef]

53. Thawarkar, S.; Khupse, N.; Shinde, D.R.; Kumar, A. Understanding the behavior of mixtures of protic-aprotic and protic-protic ionic liquids: Conductivity, viscosity, diffusion coefficient and ionicity. J. Mol. Liq. 2019, 276, 986-994. [CrossRef]

54. McLeese, S.E.; Eslick, J.C.; Hoffmann, N.J.; Scurto, A.M.; Camarda, K.V. Design of Ionic Liquids via Computational Molecular Design. Comput. Chem. Eng. 2010, 34, 1476-1480. [CrossRef]

55. Austin, N.D.; Sahinidis, N.V.; Trahan, D.W. Computer-aided molecular design: An introduction and review of tools, applications, and solution techniques. Chem. Eng. Res. Des. 2016, 116, 2-26. [CrossRef]

56. Chemmangattuvalappil, N.G. Development of solvent design methodologies using computer-aided molecular design tools. Curr. Opin. Chem. Eng. 2020, 27, 51-59. [CrossRef]

57. Klamt, A. Conductor-like Screening Model for Real Solvents: A New Approach to the Quantitative Calculation of Solvation Phenomena. J. Phys. Chem. 1995, 99, 2224-2235. [CrossRef]

58. Lin, S.-T.; Sandler, S.I. A Priori Phase Equilibrium Prediction from a Segment Contribution Solvation Model. Ind. Eng. Chem. Res. 2002, 41, 899-913. [CrossRef]

59. Farahipour, R.; Mehrkesh, A.; Karunanithi, A.T. A systematic screening methodology towards exploration of ionic liquids for $\mathrm{CO}_{2}$ capture processes. Chem. Eng. Sci. 2016, 145, 126-132. [CrossRef]

60. Chen, Y.; Woodley, J.M.; Kontogeorgis, G.; Gani, R. Integrated Ionic Liquid and Process Design involving Hybrid Separation Schemes. Comput.-Aided Chem. Eng. 2018, 44, 1045-1050.

61. Song, Z.; Zhou, T.; Qi, Z.; Sundmacher, K. Systematic Method for Screening Ionic Liquids as Extraction Solvents Exemplified by an Extractive Desulfurization Process. ACS Sustain. Chem. Eng. 2017, 5, 3382-3389. [CrossRef] 
62. Song, Z.; Zhang, C.; Qi, Z.; Zhou, T.; Sundmacher, K. Computer-aided design of ionic liquids as solvents for extractive desulfurization. AIChE J. 2018, 64, 1013-1025. [CrossRef]

63. Chao, H.; Song, Z.; Cheng, H.; Chen, L.; Qi, Z. Computer-aided design and process evaluation of ionic liquids for n-hexane-methylcyclopentane extractive distillation. Sep. Purif. Technol. 2018, 196, 157-165. [CrossRef]

64. Hessel, V.; Li, X.; Chao, H.; Mo, F.; Zhou, T.; Cheng, H.; Chen, L.; Qi, Z. Computer-aided ionic liquid design for alkane/cycloalkane extractive distillation process. Green Energy Environ. 2019, 4, 154-165.

65. Mai, N.L.; Koo, Y.-M. Computer-Aided Design of Ionic Liquids for High Cellulose Dissolution. ACS Sustain. Chem. Eng. 2016, 4, 541-547. [CrossRef]

66. Firaha, D.S.; Hollóczki, O.; Kirchner, B. Computer-Aided Design of Ionic Liquids as $\mathrm{CO}_{2}$ Absorbents. Angew. Chem. Int. Ed. 2015, 54, 7805-7809. [CrossRef] [PubMed]

67. Paduszyński, K.; Królikowski, M.; Zawadzki, M.; Orzeł, P. Computer-Aided Molecular Design of New Task-Specific Ionic Liquids for Extractive Desulfurization of Gasoline. ACS Sustain. Chem. Eng. 2017, 5, 9032-9042. [CrossRef]

68. Karunanithi, A.T.; Farahipour, R.; Dilmurat, K. Ionic Liquids: Applications by Computational Design. In Encyclopedia of Inorganic and Bioinorganic Chemistry; Wiley: Chichester, UK, 2016; pp. 1-13.

69. Peng, D.; Zhang, J.; Cheng, H.; Chen, L.; Qi, Z. Computer-aided ionic liquid design for separation processes based on group contribution method and COSMO-SAC model. Chem. Eng. Sci. 2017, 159, 58-68. [CrossRef]

70. Chen, Y.; Koumaditi, E.; Gani, R.; Kontogeorgis, G.M.; Woodley, J.M. Computer-aided design of ionic liquids for hybrid process schemes. Comput. Chem. Eng. 2019, 130, 106556. [CrossRef]

71. Venkatraman, V.; Evjen, S.; Lethesh, K.C.; Raj, J.J.; Knuutila, H.K.; Fiksdahl, A. Rapid, comprehensive screening of ionic liquids towards sustainable applications. Sustain. Energy Fuels 2019, 3, 2798-2808. [CrossRef]

72. Xu, Y.; Hanna, M.A.; Isom, L. “Green” Chemicals from Renewable Agricultural Biomass-A Mini Review. Open Agric. J. 2008, 2, 54-61. [CrossRef]

73. Kamm, B.; Kamm, M.; Soyez, K. The Green Biorefinery, Concept of Technology. In Proceeding of the first International Symposium on Green Biorefinery, Neuruppin, Germany, October 1997; Society of Ecological Technology and System Analysis: Berlin, Germany, 1998.

74. Frost, J.W.; Draths, K.M. Biocatalytic Syntheses of Aromatics from D-Glucose: Renewable Microbial Sources of Aromatic Compounds. Annu. Rev. Microbiol. 1995, 49, 557-579. [CrossRef] [PubMed]

75. Gravitis, J.; Zandersons, J.; Vedernikov, N.; Kruma, I.; Ozols-Kalnins, V. Clustering of bio-products technologies for zero emissions and eco-efficiency. Ind. Crop. Prod. 2004, 20, 169-180. [CrossRef]

76. Cherubini, F. The biorefinery concept: Using biomass instead of oil for producing energy and chemicals. Energy Convers. Manag. 2010, 51, 1412-1421. [CrossRef]

77. NREL. National Renewable Energy Laboratory [Internet]. In Biomass Research.; 2009. Available online: http://www.nrel.gov/biomass/biorefinery.html (accessed on 13 October 2020).

78. Huang, H.-J.; Ramaswamy, S.; Tschirner, U.W.; RamaRao, B.V. A review of separation technologies in current and future biorefineries. Sep. Purif. Technol. 2008, 62, 1-21. [CrossRef]

79. Spath, P.L.; Dayton, D.C. Preliminary Screening-Technical and Economic Assessment of Synthesis Gas to Fuels and Chemicals with Emphasis on the Potential for Biomass-Derived Syngas; National Renewable Energy Laboratory: Golden, CO, USA, 2003.

80. Bridgwater, A. Fast pyrolysis processes for biomass. Renew. Sustain. Energy Rev. 2000, 4, 1-73. [CrossRef]

81. Brownsort, P.A. Biomass Pyrolysis Processess: Performance Parameters and Their Influence on Biochar System Benefits; The University of Edinburgh: Edinburgh, UK, 2009.

82. Senneca, O. Kinetics of pyrolysis, combustion and gasification of three biomass fuels. Fuel Process. Technol. 2007, 88, 87-97. [CrossRef]

83. Demirbas, M.F. Biorefineries for biofuel upgrading: A critical review. Appl. Energy 2009, 86, S151-S161. [CrossRef]

84. Sun, Y.; Cheng, J. Hydrolysis of lignocellulosic materials for ethanol production: A review. Bioresour. Technol. 2002, 83, 1-11. [CrossRef]

85. Demirbaş, A. Biodiesel fuels from vegetable oils via catalytic and non-catalytic supercritical alcohol transesterifications and other methods: A survey. Energy Convers. Manag. 2003, 44, 2093-2109. [CrossRef]

86. Romano, R.T.; Zhang, R. Co-digestion of onion juice and wastewater sludge using an anaerobic mixed biofilm reactor. Bioresour. Technol. 2008, 99, 631-637. [CrossRef] 
87. Hamelinck, C.N.; van Hooijdonk, G.; Faaij, A.P. Ethanol from lignocellulosic biomass: Techno-economic performance in short-, middle- and long-term. Biomass Bioenergy 2005, 28, 384-410. [CrossRef]

88. Nishida, N.; Stephanopoulos, G.; Westerberg, A.W. A review of process synthesis. AIChE J. 1981, 27, 321-351. [CrossRef]

89. Douglas, J.M. Process synthesis for waste minimization. Ind. Eng. Chem. Res. 1992, 31, 238-243. [CrossRef]

90. Kokossis, A.C.; Yang, A. On the use of systems technologies and a systematic approach for the synthesis and the design of future biorefineries. Comput. Chem. Eng. 2010, 34, 1397-1405. [CrossRef]

91. Stephanopoulos, G.; Reklaitis, G.V. Process systems engineering: From Solvay to modern bio- and nanotechnology. Chem. Eng. Sci. 2011, 66, 4272-4306. [CrossRef]

92. $\mathrm{Ng}$, D.K.; $\mathrm{Ng}$, R.T.L. Applications of process system engineering in palm-based biomass processing industry. Curr. Opin. Chem. Eng. 2013, 2, 448-454. [CrossRef]

93. Douglas, J.M. A hierarchical decision procedure for process synthesis. AIChE J. 1985, 31, 353-362. [CrossRef]

94. Li, X.; Kraslawski, A. Conceptual process synthesis: Past and current trends. Chem. Eng. Process. Process. Intensif. 2004, 43, 583-594. [CrossRef]

95. Ng, D.; Pham, V.; Jiménez-Gutiérrez, A.; Spriggs, H. A Hierarchical Approach to the Synthesis and Analysis of Integrated Biorefineries. In Design Energy and the Environment, Proceedings of the Seventh International Conference on the Foundations of Computer-Aided Process Design; CRC Press: Boca Raton, FL, USA, 2009; pp. 425-432.

96. Conde-Mejía, C.; Jiménez-Gutiérrez, A.; El-Halwagi, M.M. Application of a Hierarchical Approach for the Synthesis of Biorefineries. In Process Design Strategies for Biomass Conversion Systems; Wiley: Chichester, UK, 2015; pp. 39-61.

97. Tey, S.-Y.; Wong, S.S.; Lam, J.A.; Ong, N.Q.; Foo, D.C.; Ng, D.K. Extended hierarchical decomposition approach for the synthesis of biorefinery processes. Chem. Eng. Res. Des. 2020, 166, 40-54. [CrossRef]

98. Stephanopoulos, G.; Westerberg, A.W. Studies in process synthesis-II. Chem. Eng. Sci. 1976, 31, $195-204$. [CrossRef]

99. Frangopoulos, C.A.; von Spakovsky, M.R.; Sciubba, E. A brief review of methods for the design and synthesis optimization of energy systems. Int. J. Appl. Thermodyn. 2002, 4, 151-160.

100. Kasivisvanathan, H.; Tan, R.R.; Ng, D.K.; Aziz, M.K.A.; Foo, D.C. Heuristic framework for the debottlenecking of a palm oil-based integrated biorefinery. Chem. Eng. Res. Des. 2014, 92, 2071-2082. [CrossRef]

101. Patel, B. A Thermodynamic Targeting Approach for the Synthesis of Sustainable Biorefineries. Comput.-Aided Chem. Eng. 2015, 37, 1283-1288.

102. Oppenheim, A.V. Study Guide for Discrete-Time Signal Processing; Prentice-Hall: Upper Saddle River, NJ, USA, 2010.

103. Benjamin, M.F.D.; Cayamanda, C.D.; Tan, R.R.; Razon, L.F. P-graph approach to criticality analysis in integrated bioenergy systems. Clean Technol. Environ. Policy 2017, 19, 1841-1854. [CrossRef]

104. Lam, H.L.; Klemeš, J.J.; Varbanov, P.S.; Kravanja, Z. P-Graph Synthesis of Open-Structure Biomass Networks. Ind. Eng. Chem. Res. 2013, 52, 172-180. [CrossRef]

105. Yeo, J.Y.J.; How, B.S.; Teng, S.Y.; Leong, W.D.; Ng, W.P.; Lim, C.H.; Ngan, S.L.; Sunarso, J.; Lam, H.L. Synthesis of Sustainable Circular Economy in Palm Oil Industry Using Graph-Theoretic Method. Sustainability 2020, 12, 8081. [CrossRef]

106. Grossmann, I.E. Review of Nonlinear Mixed-Integer and Disjunctive Programming Techniques. Optim. Eng. 2002, 3, 227-252. [CrossRef]

107. Bao, B.; Ng, D.K.; Tay, D.H.; Jiménez-Gutiérrez, A.; El-Halwagi, M.M. A shortcut method for the preliminary synthesis of process-technology pathways: An optimization approach and application for the conceptual design of integrated biorefineries. Comput. Chem. Eng. 2011, 35, 1374-1383. [CrossRef]

108. Pham, V.; El-Halwagi, M. Process synthesis and optimization of biorefinery configurations. AIChE J. 2011, 58, 1212-1221. [CrossRef]

109. Ng, R.T.L.; Ng, D.K. Systematic Approach for Synthesis of Integrated Palm Oil Processing Complex. Part 1: Single Owner. Ind. Eng. Chem. Res. 2013, 52, 10206-10220. [CrossRef]

110. Yuan, Z.; Eden, M.R. Superstructure optimization of integrated fast pyrolysis-gasification for production of liquid fuels and propylene. AIChE J. 2016, 62, 3155-3176. [CrossRef]

111. Rizwan, M.; Almansoori, A.; Elkamel, A. An overview on synthesis and design of microalgal biorefinery configurations by employing superstructure-based optimization approach. Energy Syst. 2019, 10, 941-966. [CrossRef] 
112. Fasahati, P.; Wu, W.; Maravelias, C.T. Process synthesis and economic analysis of cyanobacteria biorefineries: A superstructure-based approach. Appl. Energy 2019, 253, 113625. [CrossRef]

113. Dickson, R.; Liu, J.J. Optimization of seaweed-based biorefinery with zero carbon emissions potential. Comput.-Aided Chem. Eng. 2019, 46, 247-252.

114. Ramapriya, G.M.; Won, W.; Maravelias, C.T. A superstructure optimization approach for process synthesis under complex reaction networks. Chem. Eng. Res. Des. 2018, 137, 589-608. [CrossRef]

115. Ng, R.T.L.; Tay, D.H.S.; Ng, D.K. Simultaneous Process Synthesis, Heat and Power Integration in a Sustainable Integrated Biorefinery. Energy Fuels 2012, 26, 7316-7330. [CrossRef]

116. Ayodele, B.V.; Cheng, C.K. Biorefinery for the Production of Biodiesel, Hydrogen and Synthesis Gas Integrated with CHP from Oil Palm in Malaysia. Chem. Prod. Process Model. 2018, 11, 305-314. [CrossRef]

117. Pyrgakis, K.; Kokossis, A.C. Total Site Analysis as a Synthesis Model to Select, Optimize and Integrate Processess in Multiple-Product Biorefineries. Chem. Eng. Trans. 2016, 52, 913-918.

118. Kasivisvanathan, H.; Ng, R.T.; Tay, D.H.; Ng, D.K. Fuzzy optimisation for retrofitting a palm oil mill into a sustainable palm oil-based integrated biorefinery. Chem. Eng. J. 2012, 200, 694-709.

119. Wan, Y.K.; Sadhukhan, J.; Ng, K.S.; Ng, D.K. Techno-economic evaluations for feasibility of sago-based biorefinery, Part 1: Alternative energy systems. Chem. Eng. Res. Des. 2016, 107, 263-279. [CrossRef]

120. Wan, Y.K.; Sadhukhan, J.; Ng, D.K. Techno-economic evaluations for feasibility of sago-based biorefinery, Part 2: Integrated bioethanol production and energy systems. Chem. Eng. Res. Des. 2016, 107, 102-116. [CrossRef]

121. Mongkhonsiri, G.; Charoensuppanimit, P.; Anantpinijwatna, A.; Gani, R.; Assabumrungrat, S. Process development of sustainable biorefinery system integrated into the existing pulping process. J. Clean. Prod. 2020, 255, 120278. [CrossRef]

122. Sadhukhan, J.; Mustafa, M.A.; Misailidis, N.; Mateos-Salvador, F.; Du, C.; Campbell, G.M. Value analysis tool for feasibility studies of biorefineries integrated with value added production. Chem. Eng. Sci. 2008, 63, 503-519. [CrossRef]

123. Ponce-Ortega, J.M.; Pham, V.; El-Halwagi, M.M.; El-Baz, A.A. A Disjunctive Programming Formulation for the Optimal Design of Biorefinery Configurations. Ind. Eng. Chem. Res. 2012, 51, 3381-3400. [CrossRef]

124. Tay, D.H.S.; Ng, R.T.; Ng, D.K. Modular Optimization Approach for Process Synthesis and Integration of an Integrated Biorefinery. Comput. Aided Chem. Eng. 2012, 31, 1045-1049.

125. Ng, R.T.L.; Hassim, M.H.; Ng, D.K. Process synthesis and optimization of a sustainable integrated biorefinery via fuzzy optimization. AIChE J. 2013, 59, 4212-4227. [CrossRef]

126. Kasivisvanathan, H.; Ubando, A.T.; Ng, D.K.; Tan, R.R. Robust Optimization for Process Synthesis and Design of Multifunctional Energy Systems with Uncertainties. Ind. Eng. Chem. Res. 2014, 53, 3196-3209. [CrossRef]

127. Kelloway, A.; Daoutidis, P. Process Synthesis of Biorefineries: Optimization of Biomass Conversion to Fuels and Chemicals. Ind. Eng. Chem. Res. 2014, 53, 5261-5273. [CrossRef]

128. Kasivisvanathan, H.; Ng, D.K.; Poplewski, G.; Tan, R.R. Flexibility Optimization for a Palm Oil-Based Integrated Biorefinery with Demand Uncertainties. Ind. Eng. Chem. Res. 2016, 55, 4035-4044. [CrossRef]

129. Albarelli, J.Q.; Onorati, S.; Caliandro, P.; Peduzzi, E.; Meireles, M.A.A.; Marechal, F.; Ensinas, A.V. Multi-objective optimization of a sugarcane biorefinery for integrated ethanol and methanol production. Energy 2017, 138, 1281-1290. [CrossRef]

130. Sy, C.L.; Ubando, A.T.; Aviso, K.B.; Tan, R.R. Multi-objective target oriented robust optimization for the design of an integrated biorefinery. J. Clean. Prod. 2018, 170, 496-509. [CrossRef]

131. Martin, M.; Grossmann, I.E. On the Systematic Synthesis of Sustainable Biorefineries. Ind. Eng. Chem. Res. 2013, 52, 3044-3064. [CrossRef]

132. Caballero, J.A.; Odjo, A.; Grossmann, I.E. Flowsheet optimization with complex cost and size functions using process simulators. AIChE J. 2007, 53, 2351-2366. [CrossRef]

133. Ng, D.K.; Foo, D.C.; Tan, R.R. Automated Targeting Technique for Single-Impurity Resource Conservation Networks. Part 1: Direct Reuse/Recycle. Ind. Eng. Chem. Res. 2009, 48, 7637-7646. [CrossRef]

134. Ng, D.K.; Foo, D.C.; Tan, R.R. Automated Targeting Technique for Single-Impurity Resource Conservation Networks. Part 2: Single-Pass and Partitioning Waste-Interception Systems. Ind. Eng. Chem. Res. 2009, 48, 7647-7661. [CrossRef] 
135. Ng, D.K.; Foo, D.C.; Tan, R.R.; Pau, C.H.; Tan, Y.L. Automated targeting for conventional and bilateral property-based resource conservation network. Chem. Eng. J. 2009, 149, 87-101. [CrossRef]

136. $\mathrm{Ng}$, D.K. Automated targeting for the synthesis of an integrated biorefinery. Chem. Eng. J. 2010, 162, 67-74. [CrossRef]

137. Tay, D.H.S.; Ng, D.K.S. Automated Targeting for the Synthesis of an Integrated Biorefinery. J. Clean. Prod. 2012, 34, 38-48. [CrossRef]

138. Shabbir, Z.; Tay, D.H.S.; Ng, D.K. A hybrid optimisation model for the synthesis of sustainable gasification-based integrated biorefinery. Chem. Eng. Res. Des. 2012, 90, 1568-1581. [CrossRef]

139. Koukios, E.; Koullas, D.; Koukios, I.D.; Avgerinos, E. Critical parameters for optimal biomass refineries: The case of biohydrogen. Clean Technol. Environ. Policy 2010, 12, 147-151. [CrossRef]

140. Fernando, A.L.; Duarte, M.P.; Almeida, J.; Boléo, S.; Mendes, B. Environmental impact assessment of energy crops cultivation in Europe. Biofuels Bioprod. Biorefining 2010, 4, 594-604. [CrossRef]

141. Andiappan, V.; Ko, A.S.Y.; Lau, V.W.S.; Ng, L.Y.; Ng, R.T.L.; Chemmangattuvalappil, N.G.; $\mathrm{Ng}$, D.K. Synthesis of sustainable integrated biorefinery via reaction pathway synthesis: Economic, incremental enviromental burden and energy assessment with multiobjective optimization. AIChE J. 2015, 61, 132-146. [CrossRef]

142. Tey, T.O.; Chen, S.; Cheong, Z.X.; Choong, A.S.X.; Ng, L.Y.; Chemmangattuvalappil, N.G. Synthesis of a sustainable integrated biorefinery to produce value-added chemicals from palm-based biomass via mathematical optimisation. Sustain. Prod. Consum. 2020, 26, 288-315. [CrossRef]

143. Filho, J.F.S.D.C.; Romano, P.N.; De Almeida, J.M.A.R.; Sousa-Aguiar, E.F. Critical catalytic routes: From the conventional bioethanol production model toward the integrated biorefinery concept. Curr. Opin. Green Sustain. Chem. 2019, 20, 33-38. [CrossRef]

144. Tang, M.C.; Chin, M.W.S.; Lim, K.M.; Mun, Y.S.; Ng, R.T.L.; Tay, D.H.S.; Ng, D.K. Systematic approach for conceptual design of an integrated biorefinery with uncertainties. Clean Technol. Environ. Policy 2013, 15, 783-799. [CrossRef]

145. Tay, D.H.S.; Ng, D.K.; Tan, R.R. Robust optimization approach for synthesis of integrated biorefineries with supply and demand uncertainties. Environ. Prog. Sustain. Energy 2013, 32, 384-389. [CrossRef]

146. Cheali, P.; Quaglia, A.; Gernaey, K.V.; Sin, G. Effect of Market Price Uncertainties on the Design of Optimal Biorefinery Systems-A Systematic Approach. Ind. Eng. Chem. Res. 2014, 53, 6021-6032. [CrossRef]

147. Giuliano, A.; Poletto, M.; Barletta, D. Process optimization of a multi-product biorefinery: The effect of biomass seasonality. Chem. Eng. Res. Des. 2016, 107, 236-252. [CrossRef]

148. Čuček, L.; Martín, M.; Grossmann, I.E.; Kravanja, Z. Multi-period synthesis of optimally integrated biomass and bioenergy supply network. Comput. Chem. Eng. 2014, 66, 57-70. [CrossRef]

149. Awudu, I.; Zhang, J. Uncertainties and sustainability concepts in biofuel supply chain management: A review. Renew. Sustain. Energy Rev. 2012, 16, 1359-1368. [CrossRef]

150. Shabani, N.; Akhtari, S.; Sowlati, T. Value chain optimization of forest biomass for bioenergy production: A review. Renew. Sustain. Energy Rev. 2013, 23, 299-311. [CrossRef]

151. Cambero, C.; Sowlati, T. Assessment and optimization of forest biomass supply chains from economic, social and environmental perspectives-A review of literature. Renew. Sustain. Energy Rev. 2014, 36, 62-73. [CrossRef]

152. De Meyer, A.; Cattrysse, D.; Rasinmäki, J.; Van Orshoven, J. Methods to optimise the design and management of biomass-for-bioenergy supply chains: A review. Renew. Sustain. Energy Rev. 2014, 31, 657-670. [CrossRef]

153. Atashbar, N.Z.; Labadie, N.; Prins, C. Modelling and optimisation of biomass supply chains: A review. Int. J. Prod. Res. 2018, 56, 3482-3506. [CrossRef]

154. Mirkouei, A.; Haapala, K.R.; Sessions, J.; Murthy, G.S. A review and future directions in techno-economic modeling and optimization of upstream forest biomass to bio-oil supply chains. Renew. Sustain. Energy Rev. 2017, 67, 15-35. [CrossRef]

155. Stuart, P.R.; El-Halwagi, M.M. Integrated Biorefineries: Design, Analysis, and Optimization, 1st ed.; CRC Press: Boca Raton, FL, USA, 2013; p. 873.

156. Lo, S.L.Y.; How, B.S.; Leong, W.D.; Teng, S.Y.; Rhamdhani, M.A.; Sunarso, J. Techno-economic analysis for biomass supply chain: A state-of-the-art review. Renew. Sustain. Energy Rev. 2020, 135, 110164. [CrossRef]

157. Ng, R.T.L.; Ng, D.K.; Tan, R.R. Systematic Approach for Synthesis of Integrated Palm Oil Processing Complex. Part 2: Multiple Owners. Ind. Eng. Chem. Res. 2013, 52, 10221-10235. [CrossRef] 
158. Ng, R.T.L.; Ng, D.K.; Tan, R.R.; El-Halwagi, M.M. Disjunctive fuzzy optimisation for planning and synthesis of bioenergy-based industrial symbiosis system. J. Environ. Chem. Eng. 2014, 2, 652-664. [CrossRef]

159. Barla, F.; Nikolakopoulos, A.; Kokossis, A.C. Design of Circular Economy Plants-The Case of the Textile Waste Biorefinery. Comput. Aided Chem. Eng. 2017, 1933-1938.

160. Lichtenthaler, F.W.; Mondel, S. Perspectives in the use of low molecular weight carbohydrates as organic raw materials. Pure Appl. Chem. 1997, 69, 1853-1866. [CrossRef]

161. Wilpiszewska, K.; Spychaj, T. Chemical modification of starch with hexamethylene diisocyanate derivatives. Carbohydr. Polym. 2007, 70, 334-340. [CrossRef]

162. Wyman, C.E. Potential Synergies and Challenges in Refining Cellulosic Biomass to Fuels, Chemicals, and Power. Biotechnol. Prog. 2003, 19, 254-262. [CrossRef] [PubMed]

163. Liang, L.; Mao, Z.; Li, Y.; Wan, C.; Wang, T.; Zhang, L.; Zhang, L. Liquefaction of crop residues for polyol production. Bioresource 2006, 1, 248-256. [CrossRef]

164. Elliott, D.C. Biomass, Chemicals from. In Encyclopedia of Energy; Elsevier B.V.: Amsterdam, The Netherlands, 2004; pp. 163-174.

165. Werpy, T.; Petersen, G. Top Value Added Chemicals from Biomass_Volume I-Results of Screening for Potential Candidates from Sugars and Synthesis Gas; U.S Department of Energy: Washington, DC, USA, 2004.

166. Holladay, J.; Bozell, J.; White, J.; Johnson, D. Top Value-Added Chemicals from Biomass—Volume II-Results of Screening for Potential Candidates from Biorefinery Lignin; U.S. Department of Energy: Washington, DC, USA, 2007.

167. Skibar, W.; Grogan, G.; McDonald, J.; Pitts, M. UK Expertise for Exploitation of Biomass-Based Platform Chemicals; The FROPTOP Group: Runcorn, UK, 2009.

168. Achenie, L.E.K.; Gani, R.; Venkatasubramanian, V. Computer Aided Molecular Design: Theory and Practice, 1st ed.; Elsevier, B.V.: Amsterdam, The Netherlands, 2003; p. 404.

169. Venkatasubramanian, V.; Chan, K.; Caruthers, J.M. Computer-aided molecular design using genetic algorithms. Comput. Chem. Eng. 1994, 18, 833-844. [CrossRef]

170. Samudra, A.P.; Sahinidis, N.V. Optimization-based framework for computer-aided molecular design. AIChE J. 2013, 59, 3686-3701. [CrossRef]

171. Hechinger, M.; Voll, A.; Marquardt, W. Towards an integrated design of biofuels and their production pathways. Comput. Chem. Eng. 2010, 34, 1909-1918. [CrossRef]

172. Ng, L.Y.; Andiappan, V.; Chemmangattuvalappil, N.G.; Ng, D.K. Novel Methodology for the Synthesis of Optimal Biochemicals in Integrated Biorefineries via Inverse Design Techniques. Ind. Eng. Chem. Res. 2015, 54, 5722-5735. [CrossRef]

173. Ng, L.Y.; Andiappan, V.; Chemmangattuvalappil, N.G.; Ng, D.K. A systematic methodology for optimal mixture design in an integrated biorefinery. Comput. Chem. Eng. 2015, 81, 288-309. [CrossRef]

174. Bertran, M.-O.; Frauzem, R.; Sanchez-Arcilla, A.-S.; Zhang, L.; Woodley, J.M.; Gani, R. A generic methodology for processing route synthesis and design based on superstructure optimization. Comput. Chem. Eng. 2017, 106, 892-910. [CrossRef]

175. Chaávez-Islas, L.M.; Vasquez-Medrano, R.; Flores-Tlacuahuac, A. Optimal molecular design of ionic liquids for high-purity bioethanol production. Ind. Eng. Chem. Res. 2011, 50, 5153-5168.

176. Chong, F.K.; Foo, D.C.; Eljack, F.; Atilhan, M.; Chemmangattuvalappil, N.G. A systematic approach to design task-specific ionic liquids and their optimal operating conditions. Mol. Syst. Des. Eng. 2016, 1, 109-121. [CrossRef]

177. Liu, X.; Huang, Y.; Zhao, Y.; Gani, R.; Zhang, X.; Zhang, S. Ionic Liquid Design and Process Simulation for Decarbonization of Shale Gas. Ind. Eng. Chem. Res. 2016, 55, 5931-5944. [CrossRef]

178. Chong, F.K.; Andiappan, V.; Ng, D.K.; Foo, D.C.; Eljack, F.; Atilhan, M.; Chemmangattuvalappil, N.G. Design of Ionic Liquid as Carbon Capture Solvent for a Bioenergy System: Integration of Bioenergy and Carbon Capture Systems. ACS Sustain. Chem. Eng. 2017, 5, 5241-5252. [CrossRef]

179. Liu, X.; Zhou, T.; Zhang, X.; Zhang, S.; Liang, X.; Gani, R.; Kontogeorgis, G.M. Application of COSMO-RS and UNIFAC for ionic liquids based gas separation. Chem. Eng. Sci. 2018, 192, 816-828. [CrossRef]

180. Chen, Y.; Liu, X.; Kontogeorgis, G.M.; Woodley, J.M. Ionic-Liquid-Based Bioisoprene Recovery Process Design. Ind. Eng. Chem. Res. 2020, 59, 7355-7366. [CrossRef]

181. Wang, J.; Song, Z.; Cheng, H.; Chen, L.; Deng, L.; Qi, Z. Computer-Aided Design of Ionic Liquids as Absorbent for Gas Separation Exemplified by CO2 Capture Cases. ACS Sustain. Chem. Eng. 2018, 6, 12025-12035. [CrossRef] 
182. Ramadhan, N.J.; Wan, Y.K.; Ng, R.T.; Ng, D.K.; Hassim, M.H.; Aviso, K.B.; Tan, R.R. Life cycle optimisation (LCO) of product systems with consideration of occupational fatalities. Process. Saf. Environ. Prot. 2014, 92, 390-405. [CrossRef]

183. Cooley, M. Human-centred Systems. In Designing Human-centred Technology: A Cross-disciplinary Project in Computer-Aided Manufacturing, 1st ed.; Rosenbrock, H., Ed.; Springer: London, UK, 1989; pp. 133-143.

184. Francisco, M.; van den Bruinhorst, A.; Kroon, M.C. Low-Transition-Temperature Mixtures (LTTMs): A New Generation of Designer Solvents. Angew. Chem. Int. Engl. 2013, 52, 3074-3085. [CrossRef]

185. Peng, Y.; Lu, X.; Liu, B.; Zhu, J. Separation of azeotropic mixtures (ethanol and water) enhanced by deep eutectic solvents. Fluid Phase Equilibria 2017, 448, 128-134. [CrossRef]

186. Bakhtyari, A.; Haghbakhsh, R.; Duarte, A.R.C.; Raeissi, S. A simple model for the viscosities of deep eutectic solvents. Fluid Phase Equilibria 2020, 521, 112662. [CrossRef]

Publisher's Note: MDPI stays neutral with regard to jurisdictional claims in published maps and institutional affiliations.

(C) 2020 by the authors. Licensee MDPI, Basel, Switzerland. This article is an open access article distributed under the terms and conditions of the Creative Commons Attribution (CC BY) license (http://creativecommons.org/licenses/by/4.0/). 